\title{
Guidelines for Management of Idiopathic Normal Pressure Hydrocephalus (Third Edition): Endorsed by the Japanese Society of Normal Pressure Hydrocephalus
}

\author{
Madoka NAKAJIMA, ${ }^{1}$ Shigeki YAMADA, ${ }^{2}$ Masakazu MiYAJIMA, ${ }^{3}$ \\ Kazunari IsHII, ${ }^{4}$ Nagato KURIYAMA, ${ }^{5}$ Hiroaki KAZUI, ${ }^{6}$ Hideki KANEMOTO, ${ }^{7}$ \\ Takashi SueHIRO, ${ }^{7}$ Kenji YoshiYama, ${ }^{7}$ Masahiro KamedA, ${ }^{8}$ \\ Yoshinaga KAJIMOTO, ${ }^{9}$ Mitsuhito MASE, ${ }^{10}$ Hisayuki MuRAI, ${ }^{11}$ Daisuke KITA, ${ }^{12}$ \\ Teruo KIMURA, ${ }^{13}$ Naoyuki SAMEJIMA, ${ }^{14}$ Takahiko TOKUDA, ${ }^{15}$ \\ Mitsunobu KAIJIMA, ${ }^{16}$ Chihiro AKIBA, ${ }^{3}$ Kaito KAWAMURA, ${ }^{1}$ Masamichi ATSUCHI, ${ }^{17}$ \\ Yoshihumi HIRATA, ${ }^{18}$ Mitsunori MATSUMAE, ${ }^{19}$ Makoto SASAKI, ${ }^{20}$ \\ Fumio YAMASHITA, ${ }^{20}$ Shigeki AOKI, ${ }^{21}$ Ryusuke IRIE, ${ }^{21}$ Hiroji MIYAKE, ${ }^{22}$ \\ Takeo KATO, ${ }^{23}$ Etsuro MORI, ${ }^{24}$ Masatsune ISHIKAwA, ${ }^{25}$ Isao DATE, ${ }^{8}$ Hajime ARAI, ${ }^{1}$ \\ and The research committee of idiopathic normal pressure hydrocephalus \\ ${ }^{1}$ Department of Neurosurgery, Juntendo University Faculty of Medicine, Tokyo, Japan \\ ${ }^{2}$ Department of Neurosurgery, Shiga University of Medical Science, Ohtsu, Shiga, Japan \\ ${ }^{3}$ Department of Neurosurgery, Juntendo Tokyo Koto Geriatric Medical Center, Tokyo, Japan \\ ${ }^{4}$ Department of Radiology, Kindai University Faculty of Medicine, Osakasayama, Osaka, Japan \\ ${ }^{5}$ Department of Epidemiology for Community Health and Medicine, Kyoto Prefectural \\ University of Medicine, Graduate School of Medical Science, Kyoto, Kyoto, Japan \\ ${ }^{6}$ Department of Neuropsychiatry, Kochi Medical School, Kochi University, \\ Nankoku, Kochi, Japan \\ ${ }^{7}$ Department of Psychiatry, Osaka University Graduate School of Medicine, Suita, Osaka, Japan \\ ${ }^{8}$ Department of Neurological Surgery, Okayama University Graduate School of Medicine, \\ Dentistry and Pharmaceutical Sciences, Okayama, Okayama, Japan \\ ${ }^{9}$ Department of Neurosurgery, Division of Surgery, Osaka Medical College, Takatsuki, \\ Osaka, Japan \\ ${ }^{10}$ Department of Neurosurgery, Nagoya City University, Graduate School of Medical \\ Sciences, Nagoya, Aichi, Japan \\ ${ }^{11}$ Department of Neurosurgery, Chibaken Saiseikai Narashino Hospital, Narashino, Chiba, Japan \\ ${ }^{12}$ Department of Neurosurgery, Noto General Hospital, Nanao, Ishikawa, Japan \\ ${ }^{13}$ Department of Neurosurgery, Kitami Red Cross Hospital, Kitami, Hokkaido, Japan \\ ${ }^{14}$ Department of Neurosurgery, Tokyo Kyosai Hospital, Federation of National Public \\ Service Personnel Mutual Aid Associations, Tokyo, Japan \\ ${ }^{15}$ Department of Functional Brain Imaging Research, National Institute of Radiological \\ Science, National Institutes for Quantum and Radiological Science and Technology, \\ Chiba, Chiba, Japan \\ ${ }^{16}$ Department of Neurosurgery, Hokushinkai Megumino Hospital, Eniwa, Hokkaido, Japan \\ ${ }^{17}$ Normal Pressure Hydrocephalus Center, Jifukai Atsuchi Neurosurgical Hospital, \\ Kagoshima, Kagoshima, Japan \\ ${ }^{18}$ Department of Neurosurgery, Kumamoto Takumadai Hospital, Kumamoto, Kumamoto, Japan \\ ${ }^{19}$ Department of Neurosurgery at Tokai University School of Medicine, Isehara, Kanagawa, Japan \\ ${ }^{20}$ Division of Ultrahigh Field MRI, Institute for Biomedical Sciences, Iwate Medical \\ University, Yahaba, Iwate, Japan
}

Received August 17, 2020; Accepted October 13, 2020

Copyright $\odot 2021$ by The Japan Neurosurgical Society This work is licensed under a Creative Commons AttributionNonCommercial-NoDerivatives International License. 


\author{
${ }^{21}$ Department of Radiology, Juntendo University School of Medicine, Tokyo, Japan \\ ${ }^{22}$ Nishinomiya Kyoritsu Rehabilitation Hospital, Nishinomiya, Hyogo, Japan \\ ${ }^{23}$ Division of Neurology and Clinical Neuroscience, Department of Internal Medicine III, \\ Yamagata University School of Medicine, Yamagata, Yamagata, Japan \\ ${ }^{24}$ Department of Behavioral Neurology and Neuropsychiatry, Osaka University United \\ Graduate School of Child Development, Suita, Osaka, Japan \\ ${ }^{25}$ Department of Neurosurgery and Normal Pressure Hydrocephalus Center, Rakuwakai \\ Otowa Hospital, Kyoto, Kyoto, Japan
}

\begin{abstract}
Among the various disorders that manifest with gait disturbance, cognitive impairment, and urinary incontinence in the elderly population, idiopathic normal pressure hydrocephalus (iNPH) is becoming of great importance. The first edition of these guidelines for management of iNPH was published in 2004, and the second edition in 2012, to provide a series of timely, evidence-based recommendations related to iNPH. Since the last edition, clinical awareness of iNPH has risen dramatically, and clinical and basic research efforts on iNPH have increased significantly. This third edition of the guidelines was made to share these ideas with the international community and to promote international research on iNPH. The revision of the guidelines was undertaken by a multidisciplinary expert working group of the Japanese Society of Normal Pressure Hydrocephalus in conjunction with the Japanese Ministry of Health, Labour and Welfare research project. This revision proposes a new classification for NPH. The category of iNPH is clearly distinguished from NPH with congenital/developmental and acquired etiologies. Additionally, the essential role of disproportionately enlarged subarachnoid-space hydrocephalus (DESH) in the imaging diagnosis and decision for further management of iNPH is discussed in this edition. We created an algorithm for diagnosis and decision for shunt management. Diagnosis by biomarkers that distinguish prognosis has been also initiated. Therefore, diagnosis and treatment of iNPH have entered a new phase. We hope that this third edition of the guidelines will help patients, their families, and healthcare professionals involved in treating iNPH.
\end{abstract}

Keywords: clinical guideline, idiopathic normal pressure hydrocephalus, diagnosis, treatment, management 


\section{CONTENTS}

$\begin{array}{lr}\text { Abbreviation } & 66 \\ \text { Introduction } & 67 \\ \text { Method of Creating the Guidelines } & 68 \\ \text { Idiopathic Normal Pressure Hydrocephalus as a Concept } & 68 \\ \text { Algorithm of Diagnosis and Management } & 71 \\ \text { Chapter 1: Clinical Presentation and Initial Imaging Data } & 71 \\ \text { Chapter 2: Brain Imaging Characteristics in iNPH } & 74 \\ \text { Chapter 3: CSF investigations: CSF sample, Drainage Test, and CSF Dynamics Investigation } & 78 \\ \text { Chapter 4: Surgical Treatment } & 81 \\ \text { Chapter 5: Postoperative Management and Prognosis } & 83 \\ \text { Conclusion } & 86 \\ \text { Conflicts of Interest Disclosure } & 86 \\ \text { References } & 87\end{array}$ 


\section{Abbreviation}

A $\beta$ : amyloid $\beta$ protein

AC: anterior commissure

AD: Alzheimer's disease

AICs: antibiotic impregnated shunt catheters

AVIM: asymptomatic ventriculomegaly with features of iNPH on MRI

BPSD: behavioral and psychological symptoms of dementia

BVR: brain/ventricle ratio

CA: callosal angle

CAPPAH sign: convexity apparent hyperperfusion sign

CBF: cerebral blood flow

CHPV: Codman-Hakim programmable valve

Cout: CSF outflow conductance

CSF: cerebrospinal fluid

CT: computed tomography

DAT: dopamine transporter

DESH: disproportionately enlarged subarachnoid-space hydrocephalus

DTI: diffusion tensor imaging

EI: Evans Index

ETV: endoscopic third ventriculostomy

FA: fractional anisotropy

FAB: frontal assessment battery

FDG: fluorodeoxyglucose

GMC: Guidelines Management Committee

HC: head circumference

HDS-R Hasegawa's dementia scale-revised

ICP: intracranial pressure

iNPH: idiopathic normal pressure hydrocephalus

iNPHGS: iNPH grading scale

LBD: Lewy body disease

LOVA: longstanding overt ventriculomegaly in adults
LP: lumboperitoneal

LRG: leucine-rich $\alpha 2$-glycoprotein

MIBG: metaiodobenzylguanidine

MMSE: Mini-Mental State Examination

MRI: magnetic resonance imaging

mRS: modified Rankin Scale

NAA/Cr: N-acetylaspartate/Creatine

NFL: neurofilament light chain

NPH: normal pressure hydrocephalus

PaVM: panventriculomegaly with a wide foramen of Magendie and large cisterna magna

PC: posterior commissure

PET: positron emission tomography

PiB: Pittsburgh compound B amyloid imaging

PSP: progressive supranuclear palsy

p-tau: phosphorylated tau

PTPRQ: protein tyrosine phosphatase receptor type Q

QALY: quality-adjusted life year

RAVLT: rey auditory verbal learning test

RBMT: rivermead behavioral memory test

RCT: randomized controlled trial

$\mathrm{RI}$ : radio isotope

Rout: CSF outflow resistance

SINPHONI: Study of Idiopathic Normal Pressure Hydrocephalus on Neurological Improvement

sNPH: secondary normal pressure hydrocephalus SPECT: single-photon emission computed tomography

TMT: trail making test

t-tau: total tau

TUG: timed up \& go test

VA: ventriculo-atrial

VP: ventriculo-peritoneal

WAIS: Wechsler adult intelligence scale 


\section{Introduction}

Geriatric medical and nursing care are important contemporary topics in Japan's rapidly aging society. One of the important health conditions that disproportionately affects the elderly is normal pressure hydrocephalus (NPH), a condition characterized by gait disturbance, cognitive impairment, and urinary incontinence.

NPH was first reported by Drs. Hakim and Adams in 1965 in a case series in which they described presentations of the triadic syndrome above, along with ventricular enlargement (ventriculomegaly) despite cerebrospinal fluid (CSF) pressure being within the normal range. ${ }^{1)}$ In all cases treated in that series, symptomatic improvement was achieved by the surgical placement of a ventriculo-atrial shunt to divert CSF. ${ }^{1,2)}$ The condition was classified into idiopathic NPH (iNPH), which is of unknown origin, and secondary NPH (sNPH), in which symptoms appear subsequent to an acquired neurological injury (e.g., subarachnoid hemorrhage or meningitis). Other categories-congenital/developmental NPH and familial NPH-include cases with congenital ventriculomegaly that remained asymptomatic until advanced age, occasionally with a familial component. sNPH is not difficult to diagnose, as it tends to follow an obvious etiological event. Differential diagnosis of iNPH, in contrast, is by no means straightforward, given its gradual onset and symptomatic progression, as well as its pathological similarity to a myriad of other diseases; moreover, the hallmarks of cognitive dysfunction, gait disturbance, and urinary incontinence are more often attributable to non-specific causes in the elderly. Affected patients are frequently misdiagnosed with Alzheimer's disease and other neurodegenerative diseases, since the neuroimaging hallmarks of iNPH are difficult to distinguish from those of cerebral atrophy in general. iNPH has long been conceptualized as a form of "treatable dementia." The undue focus of past therapeutic strategies on this aspect, and the consequent over-diagnosis of iNPH, however heralded case after case of ineffective surgeries and complications thereof, leading to that concept being neglected and no longer considered as a useful clinical definition. Moreover, iNPH is a communicating hydrocephalus, which distinguishes it from sNPH following subarachnoid hemorrhage or meningitis, and the failure of past classification schemes to regard this difference has acted as a barrier to properly understanding the condition. Neither the etiology of iNPH nor any of its pathogenetic mechanisms have been elucidated till date: half a century since its first description, the prefix "idiopathic" remains stubbornly attached.
Pathological and epidemiological research have yielded valuable fundamental knowledge to facilitate the understanding of secrets of several diseases, but for iNPH, these lines of inquiry have only just begun.

Japanese Guidelines of iNPH: History and Revisions

The world's first clinical guidelines for iNPH in Japan were published in 2004, with the aim of standardizing its diagnosis and treatment and rectifying the high variability in related decisions across regions, facilities, and doctors. ${ }^{3)}$ The CSF tap test-a diagnostic test involving the drainage of CSF from the spinal canal-occupied a central dominant role within the diagnostic flowchart printed in the first edition. Clinicians' awareness of iNPH rose dramatically following the publication of the guidelines, as did the number of affected patients who were treated with CSF shunt placement; in tandem, basic and clinical researches into the condition have made tremendous strides. Recognizing the need for the global dissemination of data obtained from highevidence-level study designs during the guidelines' formulation, the authors prompted the initiation of the multicenter collaborative prospective cohort study SINPHONI (Study of Idiopathic Normal Pressure Hydrocephalus on Neurological Improvement). ${ }^{4}$ The resulting data supported the benefit of CSF shunt placement, regardless of tap test findings for cases with suspected iNPH based on clinical presentation, and who exhibit features of the so-called disproportionately enlarged subarachnoid-space hydrocephalus (DESH) on magnetic resonance imaging (MRI), that is, ventricular enlargement accompanied by shrinkage of the subarachnoid space at cerebral high convexities ("high-convexity tightness"). ${ }^{5)}$ In light of these findings, in the second edition published in 2012, the guidelines' diagnostic flowchart was revised to give the deserved priority to MRI features of DESH. ${ }^{6}$ Subsequently, Japan has seen a deluge of well-supported evidence produced by SINPHONI-2 (a randomized control trial $(\mathrm{RCT})^{7,8)}$ and a national epidemiological survey, ${ }^{9,10)}$ among other studies. In this edition, the authors have revised the guidelines once again to reflect this new evidence, under the framework of a joint undertaking between the Japanese Society of Normal Pressure Hydrocephalus and the investigators involved in Etiology, Diagnosis, and Treatment of Idiopathic Normal Pressure Hydrocephalus, a research project for rare/intractable diseases, which is sponsored by the Ministry of Health, Labour and Welfare.

\section{Objective of the guidelines}

The guidelines for the diagnosis and treatment of iNPH were developed primarily for use by clinical specialists who often encounter neurological diseases 
in the elderly (e.g., neurosurgeons, neurologists, and psychiatrists), and also to assist practicing clinicians in gerontology, internal medicine, radiology, rehabilitation, and primary care. The guidelines explicitly adopt the tenets and standards of evidence-based medicine; however, readers should not interpret this to mean that all recommendations and proscriptions in the document are based on well-supported evidence, noting that "expert opinions"- - the lowest standardare also cited as warranted. The ultimate goal of creating, disseminating, and implementing these guidelines is to provide the field with diagnostic criteria that can identify iNPH patients who would benefit from CSF shunt placement and achieve persistent long-term efficacy following treatment while preventing the condition from being overlooked in the elderly.

That being said, readers should bear in mind that these guidelines are not intended to supersede individual doctors' judgments in selecting diagnostic and therapeutic strategies. Moreover, other clinical policies may exist besides those explicitly detailed in these guidelines.

\section{Method of Creating the Guidelines}

\section{Revision history, levels of evidence, and recommendation grading determinations}

We drafted candidate clinical questions (CQs) for each of the important clinical issues identified, selected reflective keywords, and conducted literature review. Since the last edition of the guidelines was published in 2012, the scope of the review was refined to works published in or after that year in principle, identifying references published as late as June 2019. For each outcome of interest, the body of evidence available was graded using a rating sheet created by members of the systematic review team. In addition, select papers located by manual searching were incorporated into the review if deemed necessary by the Guidelines Management Committee (GMC).

The systematic review was primarily conducted using a qualitative methodology, in part because a purely quantitative review was infeasible due to insufficient number of datasets. However, a quantitative systematic review was set as the non-binding objective, to the extent deemed possible by all GMC members, in accordance with committee policy.

These guidelines consist of answers and commentary for each of the CQs, and the key answer statements are shown for easy reference at the beginning of each chapter. Evidence level was assessed based on the body of evidence available for each outcome and for each study design (RCT, observational study, etc.), rather than for each work in isolation. Evaluation criteria took into account bias risk, indirectness,
Table 1 Levels of evidence and recommendation grades

\begin{tabular}{cl}
\hline Recommendation grade & \\
1 (Strong) & Recommended \\
2 (Weak) & Suggested \\
Strength of Evidence & \\
A & Strong \\
B & Medium \\
C & Weak \\
D & Very weak \\
\hline
\end{tabular}

inconsistency, imprecision, publication bias, and other confounding factors. Guideline writing team members were responsible for drafting CQs, answers, and commentaries in designated areas; these were then discussed and decided upon by the entire GMC. The overall structure of the guideline follows in general the established algorithm of diagnosis and management of iNPH. By the steps and stages of the algorithm, there are indicators that show portions of the text in which details on the subject can be found.

Levels of evidence and grades of recommendation are shown in Table 1. Diagnostic methods and treatments are ranked using a combination of evidence level and recommendation grade: for example, "1A" refers to a strong recommendation with strong evidence; " $1 \mathrm{~B}$," a strong recommendation with moderate evidence; "2C," a weak recommendation with weak evidence; and "2D," a weak recommendation with very weak evidence. Evidence level is indicated for all possible interventions, even in relation to CQs for which a recommendation grade is not given.

The resulting rough draft of guidelines was reviewed by GMC members in evaluation and coordination roles. Review was also requested of an external committee. In November 2019, we sought public comment, considered the input received, and revised the draft accordingly.

\section{Idiopathic Normal Pressure Hydrocephalus as a Concept}

iNPH originates from impaired CSF absorption in the absence of prior illness or injury that can cause it (such as subarachnoid hemorrhage, meningitis, etc.). Gait disturbance is the most prominent symptom of iNPH, but cognitive impairment and urinary incontinence are also common. The condition progresses gradually and is frequently seen in the elderly. Symptomatic improvement can be achieved by the surgical placement of a suitable CSF shunt device.

Note that one conventional definition of iNPH includes this provision: "symptomatic improvement 


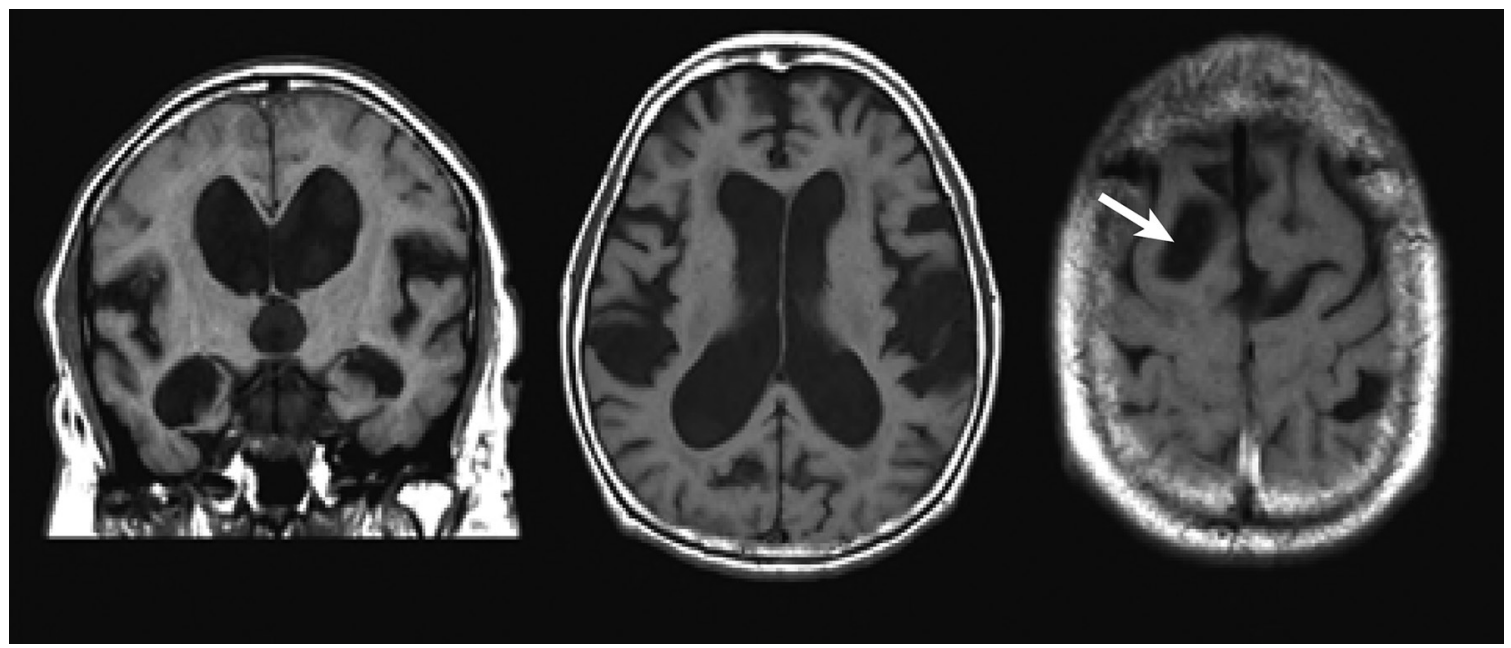

Fig. 1 DESH. Typical MRI of a patient with iNPH. Narrowing of the CSF spaces near the vertex and widening of the Sylvian fissure are good indicators that iNPH will respond to treatment. The few wide sulci that are seen on the cerebral convexity (white arrow) are all in the vicinity of large, superficial arteries. DESH: disproportionately enlarged subarachnoidspace hydrocephalus, MRI: magnetic resonance imaging, CSF: cerebrospinal fluid, iNPH: idiopathic normal pressure hydrocephalus.

achieved by CSF shunt placement.” However, since this outcome can only be measured postoperatively, the definition is unsuitable for the preoperative diagnosis of iNPH. Hence, these guidelines refer to the description above as a "concept" rather than a definition of diagnosis per se.

The implications of using a "concept" lead to the introduction of stage-like progress in the establishment of the final diagnosis after performing shunt intervention with positive outcome. Before establishing the final diagnosis, several stages are required that will allow the selection of potential candidates for shunt treatment based on best available evidence, and these stages have been designated as suspected, possible, and probable (before shunt intervention) iNPH.

Hydrocephalus may be classified in a myriad of ways, including by time of onset, age, and even cause. However, the most important distinction depends on CSF circulation in the ventricular system, with normal and impaired flow along the CSF pathways, respectively, corresponding to the so-called communicating and non-communicating hydrocephalus. How a given case of hydrocephalus should be treated strongly depends on which of the subtypes it is. Traditional classification schemes give outsized attention to morphological changes in the ventricles and rarely consider eventual alterations in the subarachnoid space.

\section{Disproportionately enlarged subarachnoid-space hydrocephalus}

In the case of iNPH, the DESH plays an essential role in imaging diagnosis and decision for further management.,5) The history of DESH began with MRI volumetry-based investigation of the imaging features of iNPH patients by Kitagaki and colleagues. ${ }^{5)}$ The authors noted signs of high-convexity/midline subarachnoid space tightness in addition to mildmoderate ventricular enlargement on coronal MRI (Fig. 1). This morphological characteristic of CSF distribution was also observed in the vast majority of iNPH cases followed up in the SINPHONI study and needed further evaluation for its clinical significance. The SINPHONI-2 study clearly indicated that such patients, in combination with the clinical triad of symptoms, have high probability of positive tap test and benefit from shunting. As the degree of impairment of CSF absorption in the spinal cord subarachnoid spaces remains unresolved, DESH seems to be a reliable radiological marker of dysfunctional CSF absorption in the cranial subarachnoid spaces. In addition, this distinguishing aspect of hydrocephalus that was poorly engaged in traditional classification schemes will surely occupy an important place in future research of the disease.

How iNPH relates to similar types of hydrocephalus

The SINPHONI trial demonstrated the value of DESH findings on brain imaging-that is, ventriculomegaly (Evans index $[\mathrm{EI}] \geq 0.3$ ), in association with high-convexity/midline tightness and Sylvian fissure enlargement, which are both signs of impaired CSF dynamics in the subarachnoid space, in combination with the classic triad of symptoms in the diagnosis of iNPH. ${ }^{4)}$ Therefore, at the early diagnostic stages, imaging plays important role in differentiating 
among the existing types of NPH. Ventriculomegaly (with EI $\geq 0.3$ ) among iNPH patients enrolled in the SINPHONI study ranged from mild to moderate (average EI: $0.356 \pm 0.040$ ), with severe enlargement rarely encountered. ${ }^{4)}$ Debate is ongoing about how to handle patients with suspected iNPH who fail to meet this criterion (i.e., with an EI $<0.3$ ), or who do not exhibit high-convexity tightening. These presentations are difficult to distinguish from mere brain atrophy, and no systematic case series has been published till date. Therefore, we simply refer to such cases collectively as "non-DESH" in these guidelines, in anticipation of a formal definition of this subtype once more data become available.

sNPH develops after an obvious antecedent CNS disease or injury (subarachnoid hemorrhage and meningitis being representative examples). Diagnosing $\mathrm{sNPH}$ is unproblematic because there is usually history of a causal event/disease before the appearance of NPH symptoms and ventriculomegaly.

International iNPH guidelines published in 2005 define the age of clinical onset of NPH as $\geq 40$ years, and that will inevitably include cases of delayed-onset congenital hydrocephalus. ${ }^{11)}$ In fact, one report claimed an unusually high prevalence of large head circumference (HC) among iNPH patients. ${ }^{12)}$ However, a major study of a large iNPH cohort found the average age of onset to be around 75 years, with very few individuals in their $40 \mathrm{~s}$ at the time of onset. ${ }^{13,14)}$

Other conditions under consideration as subtypes of delayed-onset congenital hydrocephalus include longstanding overt ventriculomegaly in adults $(\text { LOVA })^{15)}$ and panventriculomegaly with a wide foramen of Magendie and large cisterna magna $(\mathrm{PaVM}){ }^{16)}$ LOVA presents with severe lateral and third ventriculomegaly, as well as features suggestive of chronic intracranial hypertension (e.g., enlarged HC, and sella turcica enlargement and erosion). NPH-like symptoms (cognitive impairment, gait disturbance, and urinary dysfunction) start to appear in adulthood. Most cases of LOVA are non-communicating hydrocephalus accompanied by aqueductal stenosis. PaVM is characterized by enlargement of all cerebral ventricles and widening of the median aperture (of Magendie) and cisterna magna. The majority of cases exhibit pontine arachnoid septation and signs of restricted CSF dynamics in the pontine cistern. Moreover, the condition frequently co-occurs within families, suggesting a genetic component. Neuroendoscopic fenestration of the floor of the third ventricle could be indicated for LOVA and PaVM; however, some studies have reported successful symptomatic improvement in such patients following CSF shunt placement. ${ }^{17,18)}$ These two types of NPH are characterized by

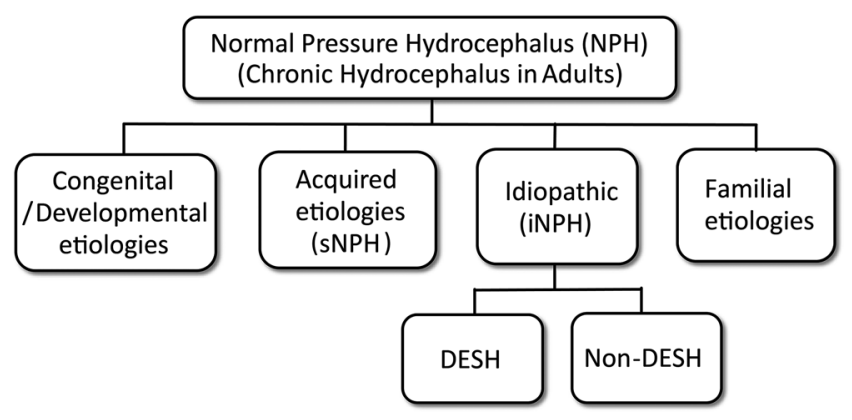

Fig. 2 Classification of hydrocephalus in Relation to iNPH. DESH: disproportionately enlarged subarachnoid-space hydrocephalus.

ventriculomegaly and NPH symptoms, and respond to CSF shunt placement in a similar way, a fact placing them in a single category of NPH that is separate from iNPH, without detectable etiology and regardless of the age of clinical onset. Given these distinctions, we would like to include these new categories within the NPH classification scheme: congenital/developmental NPH (Fig. 2). Some patients with NPH have familial aggregation, which is classified as familial NPH (Fig. 2). ${ }^{19-21)}$

\section{Epidemiology}

The majority of epidemiological studies on iNPH have been hospital-based; however, there have been some reports of population-based studies on community residents. It is difficult to compare the results of previous studies since epidemiological studies on iNPH have involved different populations and survey methods. It is also important to note the clinical and statistical heterogeneity in the results presented within the studies, depending on their survey methods, populations, and surveyed years; for example, heterogeneity has been noted in the guideline used for the diagnosis of iNPH. Here, we present data from studies carried out in Japan and other countries after classifying epidemiological studies on iNPH into (A) populationbased studies, ${ }^{22-28)}$ (B) hospital-based studies, ${ }^{9,29-33)}$ and (C) other epidemiological reports on iNPH. ${ }^{34-36)}$

\section{Population-based studies}

The prevalence of iNPH according to the international guidelines in the general population, as reported by two recent Swedish retrospective epidemiological surveys $^{27,28)}$ using head CT data, is $3.7 \%$; prevalence rates of $8.9 \%$ and $5.9 \%$ were reported in the population aged 80 years and above in both studies, suggesting that prevalence increases with age. However, the prevalence of iNPH in one of the epidemiological surveys in Sweden would be $1.5 \%$, if the researchers 
had used the criteria of the Japanese guidelines. ${ }^{27)}$ This value is virtually consistent with a weighted average of $1.6 \%$ in four population-based studies in Japan. ${ }^{22-24,26)}$

\section{Hospital-based studies}

In the hospital-based studies, the medical examination rate was reported to be 2-10 people per $100000,{ }^{9,29,30)}$ but this value increased to $30-60$ per 100000 among people aged $65-70$ years and higher. ${ }^{9,31)}$ However, the indicators of incidence, such as medical examination rate and number of patients in hospital-based studies, are based on retrospective surveys that focused on imaging and examination records, which would fail to account for low medical examination rates and overlooked patients. Therefore, we need to be aware that more iNPH patients are present among the community-dwelling older population.

\section{Other epidemiological reports on iNPH}

Few prevalence surveys focusing on iNPH have been conducted on patients with diseases such as dementia, gait disturbance, and Parkinsonism. According to a 2018 meta-analysis of $\left.\mathrm{iNPH},{ }^{36}\right)$ the mean prevalence of iNPH in the general population worldwide is 175 per 100000; it is 400 per 100000 in the population aged 80 years and above, indicating that the prevalence increases with age. The majority of epidemiological reports on this disease from Asia are from Japan, and the mean prevalence reported in these studies is 660 per 100000 . However, the mean prevalence in countries other than Japan is 53 per 100000. The prevalence of iNPH in Asia, particularly in Japan, is higher than that in Europe or North America.

\section{Asymptomatic ventriculomegaly with features of iNPH on MRI}

Asymptomatic ventriculomegaly with features of iNPH on MRI (AVIM) was defined as asymptomatic cases that exhibit iNPH features on brain MRI. ${ }^{24)}$ Eight patients with AVIM were followed up for 4-8 years in a Japanese community-based study: in that time, four of them developed iNPH (corresponding to an incidence of $6-12 \%$ per year). Thereafter, 27 of 52 AVIM cases followed up in a Japanese hospitalbased multicenter study developed iNPH within 3 years (incidence of $17 \%$ per year). This makes it clear that asymptomatic patients who exhibit features of iNPH on brain MRI should be monitored carefully due to the high risk of progressing on to iNPH.

\section{Algorithm of Diagnosis and Management}

In five chapters, the process of diagnosing iNPH is illustrated as an algorithm and explained by answering 15 CQs (Fig. 3).

\section{Diagnostic criteria for possible iNPH}

Possible iNPH is diagnosed if the following criteria are met:

1. More than one symptom in the clinical triad: gait disturbance, cognitive impairment, and urinary incontinence

2. Above-mentioned clinical symptoms cannot be completely explained by other neurological or non-neurological disease.

3. Preceding diseases possibly causing ventricular dilation (including subarachnoid hemorrhage, meningitis, head injury, congenital/developmental hydrocephalus, and aqueductal stenosis) are not obvious.

\section{Diagnostic criteria for probable iNPH}

Probable iNPH is diagnosed if a patient has all of the following three features.

1. Meets the requirements for possible iNPH

2. CSF pressure of $200 \mathrm{mmH}_{2} \mathrm{O}$ or less and normal CSF content

3. One of the following two investigational features:

(a) Neuroimaging features of narrowing of the sulci and subarachnoid space over the high-convexity/ midline surface (DESH) with gait disturbance: small stride, shuffle, instability during walking, and increase in instability on turning

(b) Improvement of symptoms after CSF tap test and/or drainage test

\section{Diagnostic criterion for definite iNPH}

The diagnosis of definite iNPH is made when objective improvement of symptoms is shown after CSF shunt surgery. This category is synonymous with "shunt responder."

\section{Chapter 1: Clinical Presentation and Initial Imaging Data}

iNPH can be suspected on grounds of clinical and/or imaging data.

\section{Characteristics and evaluation of gait disturbance}

CQ-1. What methods are available for the evaluation of gait disturbances that are characteristic of iNPH?

The degree of severity of gait disturbance can be adequately evaluated by the currently used iNPH grading scale (iNPHGS). It is recommended as a subjective evaluation scale along with other objective and quantitative evaluation methods, such as the timed up \& go test (TUG) and short-distance straight walking test.

Recommendation Grade 2, Level of Evidence C

Gait disturbance in iNPH has three characteristics: small-step gait, magnet gait, and broad-based gait. ${ }^{37-42)}$ Walking becomes unstable and slow. ${ }^{41,43)}$ 


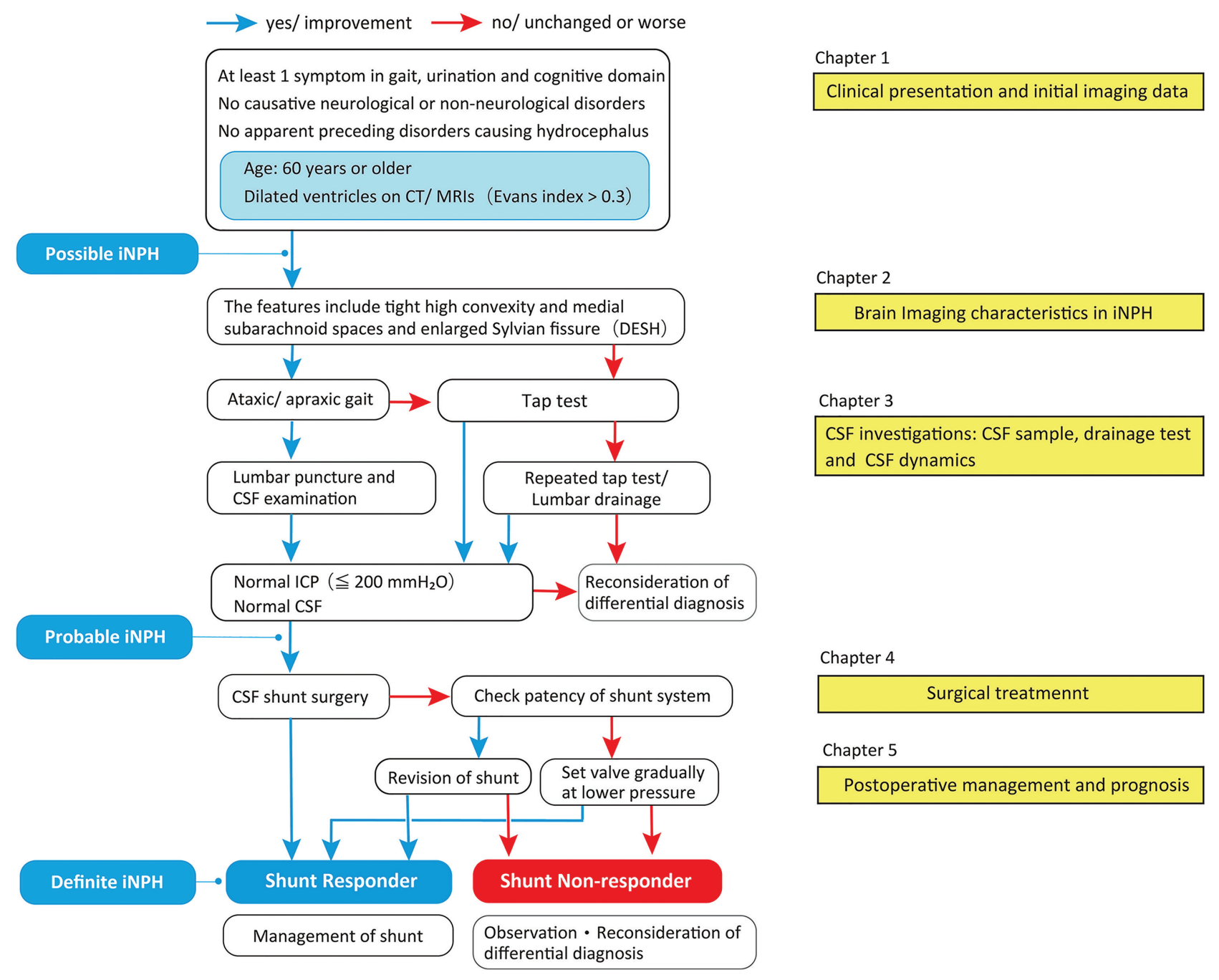

Fig. 3 Idiopathic normal pressure hydrocephalus: algorithm of diagnosis and management.

Table 2 iNPH grading scale

\begin{tabular}{llll}
\hline Grade & \multicolumn{1}{c}{ Gait disturbance } & \multicolumn{1}{c}{ Dementia } & Urinary incontinence \\
\hline 0 & Normal & Within normal range & Absent \\
1 & Unstable, but independent gait & No apparent dementia but apathetic & $\begin{array}{l}\text { Absent but with pollakiuria or } \\
\text { urinary urgency }\end{array}$ \\
2 & Walking with a cane & $\begin{array}{l}\text { Socially dependent but independent } \\
\text { at home }\end{array}$ & Sometimes at night \\
3 & Walking with two canes or a walking & Partially dependent at home & Sometimes during the day \\
4 & frame & Talking not possible & Totally dependent
\end{tabular}

iNPH: idiopathic normal pressure hydrocephalus.

When changing directions, steps are small and unstable. ${ }^{37,44)}$ Moreover, patients walk duck-footed, and the length of the strides markedly fluctuates while walking. ${ }^{40,41)}$ Freezing gait may become marked when patients first start to walk, when they are walking in a narrow place, or when they change direction. ${ }^{39)}$ Unlike in Parkinson's disease, external triggers such as command lines and landmarks have little effect on improving gait. ${ }^{41)}$ Before CSF drainage is performed, the effect of practicing cannot be seen 
when performing a multiple-step test. ${ }^{45)}$ The degree of severity of gait disturbance is described by the currently used iNPHGS (Table 2). ${ }^{46)}$ It is recommended to be used as a subjective evaluation scale along with other objective and quantitative evaluation methods such as TUG test and short-distance straight walking test. ${ }^{47)}$ Falls are known to occur readily in iNPH patients due to balance disorders, postural reflex disorder, instability, and difficulty in getting up from a chair. Patients should be interviewed to obtain a history of their falls. Although the mechanism of gait disorders is unknown, an association with the striatum ${ }^{48}$ and the corticospinal tract has been previously reported. ${ }^{49)}$

\section{iNPH grading scale}

In 2004, the Japanese committee for the first edition of this guideline proposed iNPHGS. ${ }^{3)}$ Thereafter, the reliability and validity of the iNPHGS were verified. ${ }^{46)}$ The scale items are set according to the worsening of the respective symptoms, and the levels are set to be easily defined and distinguished (e.g., for urinary incontinence, the frequency of incontinence events can be distinguished by a specific number). This was done with the purpose of adapting the scale to patients with a wide range of symptom severity. Moreover, another feature is that the item "subjective only" has been set for gait disturbance and cognitive impairment. This is because, in the early stages of iNPH, patients may be unsteady and forgetful but have no definite, objective abnormal findings. In iNPHGS, gait disturbance, cognitive impairment, and urinary incontinence are each evaluated on a scale from 0 to 4 . The total score can be used as an index, together with the evaluation points for each of the three conditions.

\section{Characteristics and evaluation of cognitive impairment}

\section{CQ-2. What methods are available for the evalua- tion of cognitive impairment in iNPH?}

The Mini-Mental State Examination, the Wechsler Adult Intelligence Scale-III digit symbol coding and symbol search tasks, and the Frontal Assessment Battery are the recommended cognitive function tests. The Rivermead Behavioral Memory Test, a parallel test, is a recommended memory test.

Recommendation Grade 2, Level of Evidence C

Even in cases of iNPH with mild symptoms, psychomotor speed is declined, and attention and working memory are impaired. ${ }^{39,50-57)}$ Although memory impairment is also observed in mildly affected patients, memory recognition is often preserved in them compared to their impairment of free recall. In addition, poor performance in word fluency tests can be seen. These functions, which are susceptible to iNPH, are closely related to the frontal lobe. Patients with severe iNPH present with generalized cognitive impairment. ${ }^{50)}$ Patients with extensive cognitive impairment have a long duration of illness and severe motor impairment. Compared with patients with Alzheimer's disease, those with iNPH have milder disorientation and memory impairment, and greater frontal lobe dysfunctions such as attention impairment, declined psychomotor speed, impaired verbal fluency, and dysexecutive syndrome. ${ }^{39,53)}$ There is no learning effect even if cognitive function tests are repeated several times before CSF drainage. ${ }^{45)}$ Cognitive impairment progresses in iNPH, unless the patient receives CSF shunting.

Although the pathophysiology of cognitive impairment in iNPH is unknown, it may have a common pathophysiology of onset as the gait disturbance..$^{39,48,49)}$ Areas that have been linked to cognitive impairment include the corpus callosum, ${ }^{57)}$ the medial frontal lobe (including the superior frontal gyrus), the anterior cingulate gyrus, ${ }^{58)}$ and the striatum. ${ }^{48)}$

Cognitive impairment in patients with iNPH is evaluated with observational scales that focused on attention and memory impairment in daily living ${ }^{37,59,60)}$. Cognitive impairment is also evaluated with cognitive tests including memory tests, ${ }^{51,61-63)}$ psychomotor speed tests, ${ }^{51,61,63)}$ attention tests, ${ }^{51,61,62,63)}$ verbal fluency tasks, ${ }^{62)}$ visuospatial tests, ${ }^{62)}$ and comprehensive cognitive tests. ${ }^{63)}$

The representative cognitive tests are the MiniMental State Examination ${ }^{64)}$ (MMSE, which can evaluate a wide range of cognitive functions), the Wechsler Adult Intelligence Scale-III (WAIS-III) digit symbol coding and symbol search tasks, which can evaluate psychomotor speed, and the Frontal Assessment Battery (FAB), which can evaluate frontal lobe function, are the recommended cognitive function tests for patients with iNPH. ${ }^{65)}$

In iNPH patients, in whom cognitive function is readily impaired and can be improved with CSF drainage, the tests generally focus on psychomotor speed, attention function, working memory, and memory function. However, psychomotor speed, attention function, and working memory also support other cognitive functions to work smoothly; therefore, improving these functions may likely improve the results of various other cognitive function tests. The international and Japanese (2nd Edition) guidelines on iNPH recommend MMSE because it is used worldwide and has been used till date in many iNPH studies. However, since memory function is relatively preserved in iNPH patients, it is desirable 
to change the word stimulus in the three-word memory tests when the MMSE is performed repeatedly over a short period.

Tests that can evaluate psychomotor speed and can be used in Japan include the digit symbol coding and symbol search tasks included in WAIS-III. ${ }^{66)}$ The fact that these tests have been standardized and much data have been published on them makes them easy to use. The Trail Making Test (TMT), especially task A, seems to reflect psychomotor speed intuitively and has been used in previous iNPH studies due to its simplicity. ${ }^{50)}$

The Stroop Test, which evaluates selective attention and suppression, and the Grooved Pegboard Test, which evaluates manual dexterity, have also been reported as useful tests for evaluating improvement after shunt intervention. ${ }^{66)}$ The Rivermead Behavioral Memory Test (RBMT), ${ }^{67)}$ which has been standardized and has four parallel tests, ${ }^{68)}$ is a useful memory test. To shorten the test time, some subtests in the RBMT, such as story recall and picture recognition, can also be used. The Ray Auditory Verbal Learning Test (RAVLT) that evaluates verbal memory has also been reported as useful in diagnosing iNPH. ${ }^{69}$

\section{Behavioral and psychological symptoms of dementia (BPSD)}

Similar to other dementia disorders, iNPH also presents with behavioral and psychological symptoms of dementia (BPSD) frequently. In iNPH, abulia/ apathy, depression, and anxiety have been commonly reported. ${ }^{70)}$ A BPSD survey conducted in Japan reported that apathy was seen at a rate of $70.3 \%$, which was a very high incidence, followed by anxiety $(25.0 \%) .{ }^{71}$ Compared with Alzheimer's disease, the frequency and severity of delusions, excitement, irritability, and depression were lower. The frequency of wandering and other abnormal behaviors was low, and stands at around 10\%. ${ }^{72}$

Apathy in iNPH has been reported as being associated with dysfunction of the caudate nucleus, ${ }^{73)}$ gait disturbance, dementia, and urinary incontinence. ${ }^{72,74,75)}$ Similar to the triad, it should be considered an important symptom of iNPH, particularly due to its high incidence and effect on the burden of caregiving.

\section{Characteristics and evaluation of urinary incontinence}

No sufficiently strong evidence to make recommendations regarding characteristics and evaluation of urinary incontinence has been found. Urge incontinence associated with an overactive bladder is characteristic of dysuria in patients with iNPH. Among patients with iNPH, $90.9 \%$ experience urine dribbling, and $74.5 \%$ urinary incontinence. ${ }^{76)}$ In an urodynamic test, detrusor hyperactivity was seen in about $70 \%$ of patients, and bladder volume was approximately $200 \mathrm{~mL}$, which is significantly smaller than the adult average. Moreover, decrease in maximum urine flow rate and increase in residual urine volume have also been observed. ${ }^{76-78)}$ Functional urinary incontinence and urge incontinence are said to be common in dementia. ${ }^{79,80)}$ Functional incontinence is suggested to affect urge incontinence due to an overactive bladder in iNPH. ${ }^{72)}$

\section{Frequency of onset of the triad and its components}

Studies that have reported in detail the frequency of onset of various symptoms of iNPH have been mainly hospital-based. The percentage of gait disturbance is $94-100 \%$, which is consistent in almost all studies and is seen in almost all iNPH cases. ${ }^{4,9,54,60,81,82)}$ The rates reported for cognitive impairment and urinary dysfunction vary, being $78-98 \%$ and $60-92 \%$, respectively. Consistently, gait disturbance is the most common symptom of iNPH, followed by cognitive impairment and urinary incontinence. Many reports state that the triad is complete in approximately $60 \%$ of cases. ${ }^{7,54,81)}$ Meanwhile, a large-scale questionnaire survey conducted in Japan in 2012 revealed that the full triad was present in only $12.1 \%$ of 1524 patients. ${ }^{9)}$

\section{Symptoms other than the triad}

In a study that evaluated neurological symptoms in 26 patients with iNPH, $84 \%$ had a snout reflex, $77 \%$ had an eyebrow reflex, $65 \%$ had paratonia (Gegenhalten), and 61\% had a palmar reflex (palmomental). ${ }^{83)}$ Moreover, a report stated that $55 \%$ of iNPH patients had bradykinesia. ${ }^{84)}$

In a study that compared eight patients with iNPH, eight with Parkinson's disease, and eight healthy controls, the iNPH group had decreased speed when lifting things and used more strength to grip things as compared to the healthy control group. This resembles the involuntary motor dysfunction of the upper limbs seen in Parkinson's disease. ${ }^{85,86)}$ However, among 127 patients with definite iNPH, Lewy body disease (LBD) was suspected in 21, and metaiodobenzylguanidine myocardial scintigraphy revealed decreased accumulation in 7 patients. ${ }^{87}$ These observations were probably due to the coexistence of Parkinson-related diseases.

\section{Chapter 2. Brain Imaging Characteristics in iNPH}

\section{Initial imaging evaluation}

iNPH is suspected when an imaging investigation detects ventricular enlargement as a preliminary diagnostic information. This finding serves as an indication for further clinical and imaging evaluation and referral. 


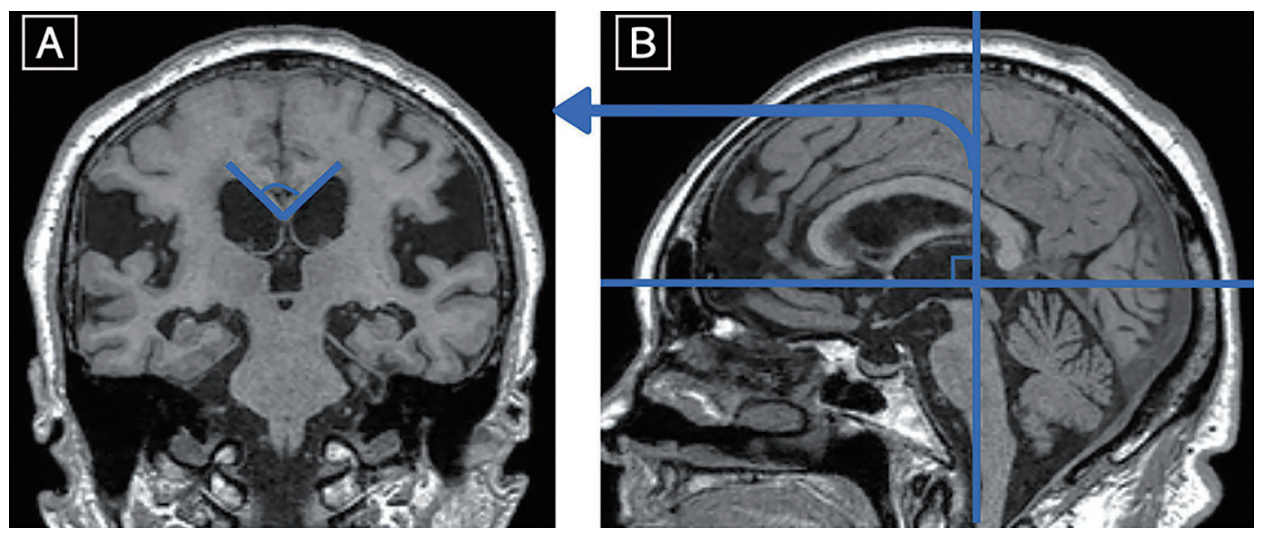

Fig. 4 Callosal angle. (A) The callosal angle, which is the angle between the left and right parts of the corpus callosum (superior walls of ventricles) should be measured on the coronal plane, (B) on a slice through the posterior commissure and perpendicular to the anterior commissure-posterior commissure line.

The most important finding in hydrocephalus is ventriculomegaly. The ratio of the maximum width of the frontal horns of both ventricles to the intracranial space width (to the inner tables of skull bone) at that site-the EI-is used to evaluate ventriculomegaly. Hydrocephalus is defined as EI $>0.3$. As ventriculomegaly can also occur as an age-related change and in neurodegenerative diseases, it cannot be used as a sign for excluding neurodegenerative diseases; moreover, ventriculomegaly can be seen in healthy elderly individuals. In patients who do not have EI $>0.3$, but have clinical criteria leading to the suspicion of iNPH, further detailed imaging, preferably with MRI, should be carried out for detection of other imaging iNPH signs.

\section{Shape and size of the cerebral ventricles and cerebral sulci}

\section{CQ-3. What images are useful for evaluating the characteristic findings of iNPH?}

DESH findings-ventriculomegaly, Sylvian fissure dilation, and narrowing of the high convexity/ midline subarachnoid spaces-are specific as iNPH imaging findings, with high positive, but low negative predictive values. Steepening of the callosal angle (CA) is available as an indirect index of the DESH findings and is useful in diagnosing iNPH and predicting the effect of a shunt intervention.

Recommendation Grade 2, Level of Evidence, C

Morphological evaluation by CT or MRI is essential not only for screening but also for diagnosing iNPH. MRI is excellent for evaluating morphological changes, and coronal plane images are particularly useful for evaluating DESH-ventriculomegaly, Sylvian fissure dilation, and narrowing of the high parietal convexity/midline subarachnoid spaces. ${ }^{4)}$ If imaging in the axial plane is performed up to the most superior (fronto-parietal) cortical areas, the diagnostic performance could be equivalent to that of coronal plane imaging. ${ }^{88)}$

Enlargement of the cerebral ventricles is considered a cardinal observation in iNPH patients, ${ }^{5,88-911}$ and the historically used EI $>0.3$ is defined as the maximum width of both frontal horns of the lateral ventricles divided by the maximum intracranial width on the same slice. Although a lot of patients with iNPH have EI $>0.3$, in some cases its value is 0.3 or less. The subarachnoid spaces are wide at or below the Sylvian fissure and narrow in the high parietal convexity region. ${ }^{5,88,92-94)}$ Additionally, some cerebral sulci may be isolated and enlarged in an oval shape (Fig. 1). ${ }^{5)}$ In other words, CSF is retained in the subarachnoid spaces located below the level of the lateral cerebral ventricles and Sylvian fissure, whereas the high parietal convexity/midline subarachnoid spaces are reduced, that is, CSF in the subarachnoid spaces exhibits an uneven distribution. Currently, it is being proposed that hydrocephalus with such characteristics should be called DESH. ${ }^{4)} \mathrm{DESH}$ is highly sensitive and specific and can be distinguished from atrophy in Alzheimer's disease. ${ }^{5,92,93)}$ Further on in iNPH management, if a patient has at least one of the triad symptoms and DESH findings on MRI, a positive response to the tap test can be expected, ${ }^{94)}$ and the effectiveness of the shunt intervention will be high. ${ }^{4}$ DESH findings normalize after shunt intervention. ${ }^{22,51)}$ Some elderly individuals have findings similar to DESH on MRI, even though they are asymptomatic (AVIM). Some of them were reported to become symptomatic a few years later. ${ }^{24)}$

Among patients diagnosed with iNPH, DESH findings were reported in $64 \%$ and non-DESH 

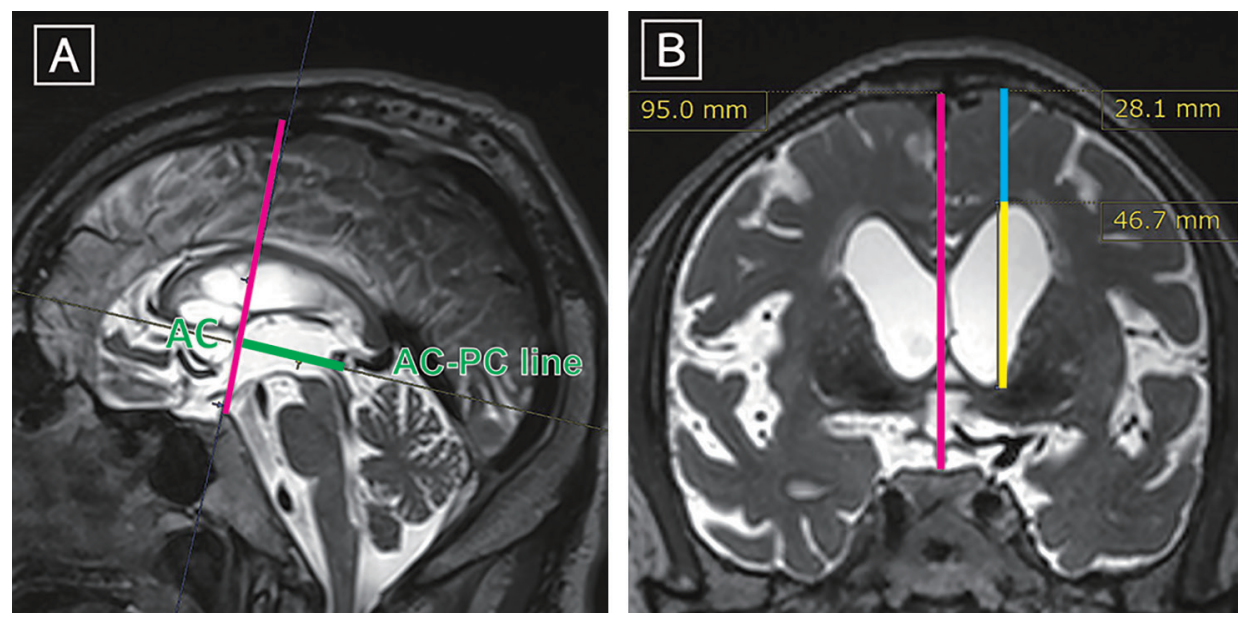

Fig. 5 z-EI and BVR. Evaluation of the z-EI and BVRs should be done on the coronal plane, (A) on a slice through the anterior commissure and perpendicular to the AC-PC line (green). (B) The height of the frontal horns of the lateral ventricles (yellow line) in the z-axis divided by the midline diameter of the skull (magenta line) is defined as the z-EI, with a cutoff value of 0.42 . The BVR at the AC levels are measured as the maximum z-axial length of the brain just above the lateral ventricles (yellow line) divided by the maximum length of the lateral ventricles (cyan line). When the coronary plane is through the AC, the value will be below 1.0, and when the plane is through the $\mathrm{PC}$, it is below 1.5. This figure shows $\mathrm{z}-\mathrm{EI}=46.7 / 95.0=0.49>0.42, \mathrm{BVR}$ at the $\mathrm{AC}$ level $=28.1 / 46.7=0.6<1.0$. AC-PC: anterior commissure-posterior commissure, BVR: brain/ventricle ratio, z-EI: z-Evans index.

findings in $36 \%$. However, with definite iNPH diagnosis, a $77 \%$ positive predictive value was shown, while the negative predictive value was as low as $25 \%{ }^{95)}$ This shows that iNPH should not necessarily be judged only based on DESH findings. In addition to DESH, there are some other specific imaging characteristics that have been observed. Callosal angle (CA), which is defined as the angle between the left and right parts of the corpus callosum (superior walls of the ventricles) and measured at the slice through the posterior commissure (PC) and perpendicular to the anterior commissure-posterior commissure (AC-PC) line, is the index that indirectly expresses DESH (Fig. 4). CA $<90^{\circ}$ is seen in most iNPH cases. ${ }^{96)}$ Since CA greatly differs depending on the measurement position and measurement method, it is necessary to standardize the measurement method. The diagnostic value of CA has been also confirmed by reports that it helps to predict the effect of shunt intervention. ${ }^{97,98)}$ Its ability to differentiate iNPH from Alzheimer's disease has a sensitivity of $97 \%$, a specificity of $88 \%$, and a positive predictive value of $93 \%$ at a cutoff value of $90^{\circ} .{ }^{96)}$ Enlargement of the lateral ventricles in iNPH usually occurs vertically on the coronal plane (z-axis) rather than along the axial plane (X-axis). ${ }^{99}$ ) Therefore, the z-EI, which is defined as the height of the frontal horns of the lateral ventricles in the z-axis direction divided by the midline diameter of the skull, with a cutoff value of 0.42 is superior to EI $>0.3$ (Fig. 5A). ${ }^{99)}$ In the same coronal plane, the brain per ventricle ratios (BVRs) at the AC and PC were calculated as the maximum width of the brain just above the lateral ventricles divided by the maximum width of the lateral ventricles on the reference coronal planes at the AC and PC levels, respectively. ${ }^{100)}$ BVR measured at the slice through the $\mathrm{AC}$ and perpendicular to the AC-PC line is $<1.0$ in iNPH (Fig. 5B), and BVR measured at the slice through the PC is $<1.5$. In addition, expansion of the inferior horn of the lateral ventricle has been reported to be useful for predicting the effectiveness of a CSF shunt intervention. ${ }^{96}$ ) Therefore, even if $\mathrm{EI}$ is $<0.3$, but the other indices meet the conditions of expanded inferior horn of the lateral ventricle, such as CA $<90^{\circ},{ }^{96,101)} \mathrm{z}$-EI $>0.42,{ }^{99)} \mathrm{BVR}$ at AC level $<1.0$, and/or BVR at PC level $<1.5,{ }^{100}$ it is acceptable to diagnose possible iNPH. Moreover, a sagittal plane MRI will reveal that the posterior part of the cingulate sulcus is narrower than the anterior (in healthy controls, either they are equal, or the anterior part is narrower than the posterior). ${ }^{102)}$ All these findings are useful for differential diagnosis from Alzheimer's disease.

Compared to Alzheimer's disease, atrophy of the hippocampus is mild in $\mathrm{iNPH}^{103)}$ and dilation of the parahippocampal sulcus is not so significant. ${ }^{5,89,91)}$ It has been reported that the cross-sectional area or diameter of the midbrain decreases in iNPH and correlates with gait disturbance, ${ }^{104)}$ and that the midbrain diameter increases after a shunt intervention. ${ }^{105)}$ However, there are conflicting reports ${ }^{106,107)}$ 
stating the opposite, and the diagnostic value of these findings is not yet clear. Similar observations have been reported that the cross-sectional area of the corpus callosum in iNPH is smaller than in healthy controls and that it increases after shunt intervention, the degree of increase correlating with improvement in cognitive impairment. ${ }^{57)}$ In brief, cerebral ventricles, Sylvian fissure, high convex cortical, and medial CSF volumes, intracranial volume ratio, and subarachnoid spaces vertical volume ratio are reported to be useful for differentiating iNPH from Alzheimer's disease. ${ }^{99,101,108-110)}$ Again, the diagnostic value (power of evidence) of these last observations remains unclear.

\section{Changes in the deep periventricular white matter}

\section{$C Q-4$. Is it recommended to utilize advanced diffusion MRI in addition to standard MRI scans for patients with suspected iNPH?}

Abnormalities are found in the diffusion index of nerve fibers by diffusion tensor imaging, mainly in the periventricular and deep white matter, and increased fractional anisotropy of the dispersion in the corticospinal tract is characteristic.

Recommendation Grade 2, Level of Evidence C

Changes in the deep periventricular white matter (the so-called leukoaraiosis) on CT and MRI are more frequently observed in patients with severe iNPH, compared with healthy elderly individuals. It is not an essential finding, but rather suggests associated ischemic complications. ${ }^{61,111)}$ The extent of change in the white matter has been reported to be inversely correlated with the tap test response. ${ }^{43)}$ However, improvement of changes in the deep periventricular white matter after shunt intervention has yielded controversial results. ${ }^{59,112)}$

Diffusion tensor imaging (DTI) is also reported to be useful for diagnosis of iNPH. ${ }^{1{ }^{13-115)}}$ Abnormalities in the periventricular white matter on DTI are detected in iNPH patients, and the finding of increased fractional anisotropy (FA) in the corticospinal tract is specific to iNPH. ${ }^{116-124)}$ Changes in the quantitative value after a shunt intervention have been reported to be correlated with the level of improvement in the clinical symptoms. ${ }^{114,122)}$

Furthermore, studies using diffusion kurtosis imaging, ${ }^{125)}$ q-space imaging, ${ }^{126)}$ and neurite orientation dispersion and density imaging ${ }^{127,128)}$ as advanced diffusion MRI techniques have been conducted. However, for these last methods, there are only a few reports, and their diagnostic value has not been established.

\section{Other imaging methods}

The studies on phase-contrast MRI reported that CSF flow velocity, pulsatile flow, stroke volume, and pressure gradient in the cerebral aqueduct significantly increase in iNPH. ${ }^{129-131)}$ The sensitivity and specificity of aqueductal stroke volume for diagnosis of iNPH were reported as $78-85 \%$ and $100 \%$, respectively. ${ }^{130)}$ It has also been reported that the stroke volume and reversed flow rate can predict the effect of shunt intervention ${ }^{132-134)}$ and tend to normalize after the intervention. ${ }^{134)}$ Their measurement accuracy has been verified in recent years. ${ }^{135)}$ However, the superiority of high aqueductal stroke volume on phase-contrast MRI over other imaging indices is not clear, and its diagnostic value has not been established.

It has been reported that proton magnetic resonance spectroscopy shows significant decrease in the N-acetylaspartate/creatine (NAA/Cr) ratio in the frontal lobe white matter and thalamus ${ }^{136,137)}$ and a peak in lactate is seen in the cerebral ventricles in iNPH. ${ }^{138)}$ Although the NAA/Cr ratio reportedly increases after surgery and correlates with improvement in cognitive function, ${ }^{58)}$ there are also negative reports, ${ }^{139,140)}$ and its diagnostic value has not been established.

\section{Nuclear diagnostic methods}

\section{CQ-5. What are the characteristic nuclear medicine findings of iNPH?}

Nuclear medicine diagnostic methods such as singlephoton emission computed tomography show decreased cerebral blood flow in the anterior parts of the cerebral hemisphere and Sylvian fissure periphery, and increased blood flow in high cortical areas (convexity apparent hyperperfusion [CAPPAH] sign).

Recommendation Grade 2, Level of Evidence B

Cerebral blood flow (CBF) pattern on single-photon emission computed tomography (SPECT) reflects the morphological changes of DESH in iNPH. The finding on SPECT is decreased CBF around the Sylvian fissure and relatively increased CBF around the high parietal lesion. This CBF pattern, which is specific to iNPH, is called convexity apparent hyperperfusion (CAPPAH). ${ }^{141,142)}$ The CBF pattern of hypoperfusion around high parietal lesion was confirmed in $58 \%$ of patients with the frontal dominant hypoperfusion type, $12 \%$ with the posterior dominant type, and $30 \%$ with the mixed type, but the effect of shunt intervention could not be predicted. ${ }^{143)} \mathrm{CBF}$ around high parietal lesion in the shunt-effective group was reported to be lower than 
in the shunt-non-effective group. Acetazolamideenhanced SPECT showed that increase in CBF after acetazolamide administration could predict improvement in cognitive function of iNPH patients after shunt intervention. ${ }^{144)}$ However, the acetazolamide test on SPECT is not commonly performed in suspected iNPH patients. In the iNPH patients who had improved urinary incontinence after shunt intervention, CBF in the middle cingulate gyrus was increased after the shunt intervention. ${ }^{145)}$ Urinary incontinence was also reported to be correlated with decreased CBF in the right frontal lobe. ${ }^{146)}$

Some more recent nuclear diagnostic techniques, such as dopamine transporter scintigraphy, have been studied in iNPH. ${ }^{147)}$ However, there are still no well-constructed reports on dopamine transporter scintigraphy in iNPH, and evidence of its usefulness is awaited.

A study on fluorodeoxyglucose-positron emission tomography (FDG-PET) reported that decreased glucose metabolism in the basal ganglia is useful for differentiating iNPH from other degenerative diseases. ${ }^{148)}$ In addition, decreased cerebral glucose metabolism in iNPH improved after shunt intervention. ${ }^{149,150)}$

Amyloid positron emission tomography (PET) study reported that amyloid deposition was observed in some cases of iNPH. ${ }^{151-154)}$ However, amyloid deposition does not necessarily signify Alzheimer's pathology and its presence will not exclude the need for shunt intervention.

\section{Chapter 3. CSF Investigations: CSF Sample, Drainage Test, and CSF Dynamics Investigation}

\section{The CSF drainage test (tap test)}

\section{CQ-6. Do the tap test and continuous drainage test have predictable therapeutic efficacy?}

The CSF drainage test (tap test) is useful for diagnosing iNPH and predicting the therapeutic effect of a shunt intervention.

\section{Recommendation Grade 1, Level of Evidence B}

\section{CQ-7. How soon after a CSF drainage test should the results be evaluated?}

It is recommended that the CSF tap test is evaluated within 24 hours after CSF removal and multiple evaluations should be done for up to a week. Cognitive impairment and urinary dysfunction are expected to improve subsequently after gait improvement, but there is no established evidence regarding the timing of this.

Recommendation Grade 2, Level of Evidence C

The CSF tap test is widely used for diagnosing and predicting the therapeutic effect of a shunt intervention, based on the changes in clinical symptoms of gait disturbance, cognitive impairment, and urinary incontinence. ${ }^{42,44,54,63,155-181)}$ Although the changes in clinical symptoms before and after the CSF drainage test are evaluated using various scales around the world, the iNPHGS is widely used as a simple scale whose reliability and validity have been verified. ${ }^{7,8,46,168,181-183)}$ Objective and quantitative evaluations on TUG test, short-distance straight walking test, MMSE, and video-viewing rating of gait disturbance are recommended. ${ }^{44,158,162,171,174,184,185,186)}$ Congruently, pathological gait features, such as small-step gait (short length of stride), broad-based gait (increasingly large step intervals), instability, difficulty in changing directions, frozen gait (no first step taken), and shuffle (dragging of feet and decreased elevation), should be evaluated by video-viewing of the TUG test.

The CSF tap test has a sensitivity of $58 \%$ (26-87\%) and a specificity of $75 \%(33-100 \%)$ as reported in systematic reviews. ${ }^{169)}$ If the triad symptoms improve after the CSF tap test, the diagnosis is highly likely to be iNPH, and the symptoms are expected to be improved by a shunt intervention. However, if a tap test does not result in any improvement, iNPH cannot be excluded, and caution is required regarding the possibility that the symptoms will improve (false negatives) by a shunt intervention. ${ }^{161,162,165,169,170,174,177,178,181)}$ In particular, the longer the period between appearance of symptoms and CSF drainage, the higher the frequency of false negatives. However, symptoms may improve after a shunt intervention, even if they do not respond to the tap test. ${ }^{181)}$

There is controversy about whether to repeat the tap test, perform continuous drainage, or perform shunt intervention if a false-negative response to the CSF tap test is suspected. It has not been established whether the continuous CSF drainage test is more predictive of the efficacy of a shunt intervention than the CSF tap test. If both the typical symptoms (gait disturbance, cognitive impairment, and urinary incontinence) and imaging findings (DESH) are present, a shunt intervention is likely to improve the symptoms in the absence of other comorbidities. ${ }^{7,8)}$

In the tap test, there is no difference in the positive detection rate, sensitivity, and specificity with respect to the amount of CSF removed, in the range of 30-50 ml. ${ }^{23)}$ The evaluation method and timing of assessing changes in clinical symptoms are more important than the volume of CSF removed. Evaluation should be performed 2-4 hours after the tap test and on the following day (approximately 24 hours later). ${ }^{155,156,158,161,162,166,168,170,173,175,176,178,179,181)}$ It should be performed at least on the following day, and as symptoms may improve from the following day 
onward, it is recommended that evaluations be performed multiple times within the first week. In a single-center retrospective observational study, walking function improved on day 2 (48 hours later) after the tap test. However, the degree of improvement decreased after day $3 .{ }^{173)}$ In the SINPHONI-2 study, cognitive impairment and urinary incontinence tended to improve later than gait disturbance and were evaluated within one week of the tap test.7,8) In addition, although there is a report stating that MMSE did not improve the day after the tap test but improved 1 week later, ${ }^{167)}$ evidence on the optimal evaluation time for changes in the respective symptoms has not yet been established.

\section{Normal pressure (diagnosis)}

\section{CQ-8. Are "intracranial pressure monitoring" and CSF dynamics tests useful for diagnosing iNPH and determining indications for CSF shunt placement?}

Intracranial pressure monitoring and CSF dynamics tests are useful for diagnosing iNPH and determining the indications for CSF shunt placement, particularly if basal CSF pressure is increased, frequency of B-waves during sleep is high, and CSF pressure pulse waves are high. High outflow resistance (Rout) of the CSF measured by infusion test correlates with effective shunt intervention.

Recommendation Grade 2, Level of Evidence C

\section{(A) Pressure and properties of CSF}

$\mathrm{CSF}$ is colorless and clear, like water. Although there are many reports stating that the upper normal pressure limit of CSF is $200 \mathrm{mmH}_{2} \mathrm{O}^{54)}$ or $180 \mathrm{mmH}_{2} \mathrm{O},{ }^{1)}$ even with values higher than this, the possibility of iNPH cannot be ruled out. It is necessary to exclude other diseases such as benign intracranial hypertension and carcinomatous meningitis. There is no clear documentation on the normal lower limit of CSF pressure in the elderly.

(B) Continuous intracranial pressure measurement (ICP monitoring)

The measurement time is approximately 12-48 hours, mainly at night. The measurement site is most commonly the lumbar cistern. ${ }^{62,187-189)}$ Pressures reportedly measured at other sites are cerebral parenchymal pressure, ${ }^{187,190,191)}$ intraventricular pressure, ${ }^{62)}$ and epidural pressure. ${ }^{192,193)}$ As such, the invasiveness of ICP measurement is high compared to the tap or infusion test. Therefore, it is only used when ICP monitoring becomes necessary, such as in cases where a lumbar puncture cannot be performed, and in those with marked enlargement of the cerebral ventricles if it is unclear whether they have arrested or symptomatic hydrocephalus. ${ }^{187)}$ This method is rarely used for diagnosing iNPH. The main parameters of ICP monitoring are as follows:

(1) Intracranial basal pressure

The threshold of basal pressure is set at around 7-15 mmHg, and most patients with iNPH have an upper limit of normal pressure. The value of the test is controversial: when basal pressure is high, the efficacy of a shunt intervention is assumed to be also high, ${ }^{193-195)}$ but there are cases in which there is no correlation. ${ }^{190,191,196)}$

(2) Pressure wave

B-waves appear more frequently during sleep, especially during the rapid eye movement sleep phase. ${ }^{189)}$ The more frequently they appear $(\geq 15 \%$ of all records), the more effective shunt intervention has been reported to be, ${ }^{187,193)}$ but there are also reports stating that there is no correlation. ${ }^{62,189,191,197)}$

(3) CSF pulse pressure

In the effective shunt intervention groups of several studies, increase in amplitude and decrease in latency were observed, ${ }^{62,195,197-199)}$ and the average value (high wave relative frequency) of the three highest wave amplitudes was often $9 \mathrm{mmHg}$ or higher (positive prediction rate of $96 \%$ ). The correlation between amplitude and pressure is considered to be high. ${ }^{62)}$

(C) CSF infusion test

The CSF infusion test is a method for examining CSF circulatory dynamics by injecting physiological saline or artificial CSF into the CSF spaces. The values differ according to the injection site (lumbar region), ${ }^{51,166,187,193,200-202)}$ infusion speed (constant speed of injection ${ }^{51,187,193,202,203)}$ or rapid infusion ${ }^{201)}$ ), and ICP measurement site (lumbar subarachnoid space pressure $^{166,187,193,200,202)}$ or epidural pressure ${ }^{193)}$ ). There are many reports on the sustained CSF infusion method, mainly in Europe. However, the results are not affected by meningeal or brain parenchymal lesions. The rapid infusion and continuous infusion methods are widely used. The main parameters are as follows:

(1) CSF outflow resistance

As shunt intervention is a surgery that lowers the outflow resistance of CSF (Rout), measuring the Rout may be useful in predicting the effectiveness of a shunt intervention..$^{51,187,193,200)}$ Rout has been found to be significantly higher in effective shunt intervention groups, and the positive prediction rate was reported to be $\geq 80 \% .^{51,187,193,200)}$ Many reports state that the absolute value of Rout and the effective/ ineffective threshold is around $14-20 \mathrm{mmHg} / \mathrm{mL} /$ min (positive prediction rate $80-92 \%$ ). ${ }^{51,187,193,200)}$ However, Rout measured in the spinal CSF compartment may not correctly reflect the Rout of the cerebral ventricular space or the entire cerebrospinal space. Moreover, there are cases in which a shunt 
Table 3 CSF biomarkers for distinguish iNPH from normal control and Alzheimer's disease

\begin{tabular}{lll}
\hline & \multicolumn{1}{c}{ Differential diagnosis } & Predict poor CSF shunt effect \\
\hline A 342 & No change compared to AD, lower than NC & Low value \\
p-tau & Lower than AD, no change compared to NC & High value \\
t-tau & Lower than AD, no change compared to NC & High value \\
NFL & Higher than NC & High value \\
LRG & Higher than NC & High value \\
A 338 & No change compared to AD, lower than NC & \\
A $\beta 40$ & No change compared to AD, lower than NC & \\
PTPRQ & Higher than NC & \\
Brain-type transferrin & Lower than NC & \\
\hline
\end{tabular}

A $\beta$ : amyloid $\beta$ protein, AD: Alzheimer's disease, CSF: cerebrospinal fluid, iNPH: idiopathic normal pressure hydrocephalus, LRG: leucine-rich $\alpha 2$-glycoprotein, NC: normal control, NFL: neurofilament light chain, p-tau: phosphorylated tau, PTPRQ: protein tyrosine phosphatase receptor type Q, t-tau: total tau.

intervention was effective even though the Rout was low. ${ }^{178,192,196,197)}$

The standard value of Rout differs according to the testing method used. It is not constant due to differences in injection conditions, and different standards have been set up. However, all reports agree that the efficacy rate of a shunt intervention is high when Rout is high. ${ }^{178,187,192,193,195,200)}$

(2) CSF outflow conductance

CSF outflow conductance (Cout) is reported to be significantly lower in effective shunt intervention groups, ${ }^{166,193,202)}$ and the Cout effective/non-effective threshold is said to be $0.08 \mathrm{~mL} / \mathrm{min} / \mathrm{mmHg}$ (positive prediction rate of $74-76 \%) .{ }^{166,200)}$ However, there is no high-level evidence showing that it is useful for diagnosing iNPH.

\section{CSF biomarkers}

\section{CQ-9. Which CSF evaluations are useful for diag- nosing iNPH and predicting its prognosis?}

Amyloid $\beta 42$ (A $\beta 42$ ) in the CSF of patients with iNPH showed lower values than in healthy subjects. Phosphorylated tau (p-tau) and total tau (t-tau) were low compared to patients with Alzheimer's disease. Measurement of $A \beta 42$, p-tau, and t-tau in the CSF is useful for the differential diagnosis of Alzheimer's disease.

Recommendation Grade 2, Level of Evidence B

Although there is no CSF biomarker with high sensitivity and specificity that predicts the effect of a CSF shunt intervention, measurement of $A \beta 42$, p-tau, t-tau, neurofilament light chain, and leucinerich $\alpha 2$ glycoprotein in the CSF can be referenced for predicting the effect of a CSF shunt intervention.

Recommendation Grade 2, Level of Evidence C
CSF evaluation is important for differentiating secondary hydrocephalus due to conditions such as meningitis and subarachnoid hemorrhages. In recent years, CSF biomarkers have been measured to diagnose iNPH and distinguish it from other neurodegenerative diseases. Among these biomarkers, those that showed consistent results in at least two studies are presented in Table 3.

A $\beta 42$, phosphorylated tau (p-tau), and total tau (t-tau) in CSF are the biomarkers with the most consistent results across studies. They can likely help to differentially diagnose iNPH and Alzheimer's disease/healthy subjects. ${ }^{204-217)}$ However, these have been reported as biomarkers that reflect pathological changes in Alzheimer's disease and are not specific markers of iNPH.

Leucine-rich $\alpha 2$ glycoprotein (LRG), ${ }^{218)}$ protein tyrosine phosphatase receptor type Q (PTPRQ), ${ }^{219)}$ and brain-type transferrin ${ }^{220}$ were first identified in Japan as proteins that vary specifically in iNPH patients based on a comprehensive proteomic analysis of CSF protein. However, subsequent studies have shown that LRG is also increased in neurodegenerative diseases, such as progressive supranuclear palsy (PSP) and LBD, and have reported that it is not a specific marker for iNPH. It is reported that PTPRQ and brain-type transferrin are derived from the choroid plexus. PTPRQ increases and brain-type transferrin decreases in patients with iNPH as compared to healthy subjects and patients with Alzheimer's disease. However, the kinetics of these biomarkers in neurodegenerative diseases other than Alzheimer's disease is unknown, and it is necessary to verify their sensitivity and specificity for the diagnosis and differential diagnosis of iNPH in the future. There are still no biomarkers with strong evidence that can differentiate and determine the 
coexistence of iNPH with neurodegenerative diseases, other than Alzheimer's disease and vascular dementia.

Although there are still no highly sensitive and specific CSF biomarkers that can predict the effect of a CSF shunt intervention, $A \beta 42$, p-tau, t-tau, neurofilament light chain (NFL), and LRG have been reported in multiple studies. ${ }^{221)}$ However, these biomarkers do not specifically reflect the pathology of iNPH.

\section{Chapter 4. Surgical Treatment}

\section{Effectiveness of shunt treatment}

\section{CQ-10. Which surgical methods most effectively ameliorate iNPH symptoms?}

CSF shunt intervention is effective for treating iNPH.

Recommendation Grade 1, Level of Evidence B

Surgical methods applied for iNPH treatment, similar to the general surgical methods for communicating hydrocephalus, are shunt interventions with ventriculo-peritoneal (VP), ventriculo-atrial (VA), or lumbo-peritoneal (LP) shunts, and they are effective.

iNPH patients with severe white matter lesions were randomly allocated to a shunt patency group and a ligation group. Three months later, in the ligation group, patency was restored, and follow-up observation was performed up to 6 months post-surgery. Symptoms improved quickly in the shunt patency group. However, in the shunt ligation group, the symptoms did not improve during the 3-month ligation period after the surgery. Meanwhile, 3 months following this, after the ligation was removed, the symptoms were reported to improve. ${ }^{222)}$

Around the world, VP shunt placement is commonly performed. However, in Japan, a nationwide survey in 2012 showed that VP shunts were made for $43.2 \%$, LP shunts for $55.1 \%$, and VA shunts for $1.7 \%$ of all treated iNPH patients. ${ }^{9}$ Although the effects of each treatment method have been reported, no report has compared them in a prospective and randomized manner. The methods used to evaluate the effectiveness of shunt interventions differ according to the study, and there are differences in the improvement rates by symptom. In the SINPHONI-2 study, which is a multicenter randomized comparative study involving 20 institutions in Japan, it became evident that the LP shunt intervention was effective. ${ }^{7)}$ At least 1-point improvement on the modified Rankin Scale (mRS) and iNPHGS after 12 months of the shunt intervention were almost the same in patients treated with VP shunt surgery (SINPHONI) and those treated with LP shunt surgery (SINPHONI-2). ${ }^{8)}$ No significant difference between the surgical procedures was detected. The rates for serious adverse events were $22 \%$ in the LP and $15 \%$ in the VP shunt groups, respectively, and the corresponding values for non-serious adverse events were $27.6 \%$ and $20 \%$. Complications due to CSF over-drainage are more common with LP than with VP shunts. After an LP shunt intervention, CSF may leak from the puncture site immediately after the puncture, and symptoms of over-drainage such as headache may appear. In this case, it may be preferable to place the patient on proactive bed rest rather than to change the valve pressure setting.

The Japanese nationwide survey also showed improvement on the mRS-in the VP shunt group ( $\mathrm{n}=417$ ), it was from 2.73 (standard deviation (SD) $=0.76)$ to $2.01(\mathrm{SD}=0.92)$, and in the LP shunt group ( $\mathrm{n}=540)$, from 2.66 ( $\mathrm{SD}=0.76)$ to 1.98 (SD $=0.93$ ). The complication rates were $10 \%$ in the $\mathrm{VP}$ shunt group and $14 \%$ in the LP shunt group, without statistically significant difference between the two groups. ${ }^{10)}$ In cases of shunt malfunction due to obstruction, tube replacement was performed in about $1 \%$ of patients in the VP shunt group, but in $6.8 \%$ in the LP shunt group, which was clearly higher. Thus, LP shunts are not recommended if spondylosis is severe and CSF communication is hindered.

In addition, no statistically significant difference was found in the reports comparing surgical complications between the VA $(\mathrm{n}=150,36 \%)$ and VP shunts ( $\mathrm{n}=346,42.5 \%$ ). However, subdural hematomas due to CSF over-drainage were significantly more frequent in the VA shunt group $(12.7 \%)$ than in the VP shunt group $(5.5 \%)(p=0.006)$. Shunt occlusion and repeated interventions were reported to be significantly less frequent in VA shunts $(6.7 \%$ and $10.7 \%$ ) than in VP shunts $(15.3 \%$ and $28.9 \%) .23$.

Cardiopulmonary complications, nephritis, and renal failure are recognized as serious complications of the VA shunt intervention. ${ }^{224-228)}$ However, the incidence of these is less than $1 \%$. VA shunt is recommended in situations where intraperitoneal adhesions are expected, such as after multiple abdominal surgeries, but not recommended if heart disease is present.

The efficacy and safety of endoscopic third ventriculostomy (ETV) have been compared to those of VP shunts with fixed pressure valve in iNPH patients who responded to the tap test. An RCT of 42 Brazilian iNPH patients, in a systematic review of the Cochrane library, showed that $50 \%$ of patients who underwent ETV achieved symptomatic improvement 12 months after the surgical intervention, whereas the VP shunt intervention achieved improvement in $76.9 \%$ of the patients. ${ }^{229)}$ However, some patients with congenital/developmental and familial $\mathrm{NPH}$ such as $\mathrm{PaVM}^{230)}$ and LOVA, ${ }^{15)}$ which show 
downward displacement of the floor of the 3rd cerebral ventricle may have also been included. A comparison of 652 patients who underwent ETV for iNPH and 12,845 patients who underwent VP shunt intervention from 2007 to 2010 in the USA showed a mortality of $3.2 \%$ vs. $0.5 \%$, respectively, and surgical complication rates of $17.9 \%$ vs. $11.8 \%$, respectively, suggesting that ETV has a higher risk compared to shunt intervention. ${ }^{231)}$

iNPH as defined in these Japanese guidelines is clearly distinguished from late-onset congenital NPH, including PaVM, LOVA, and familial NPH. ETV treatment for communicating hydrocephalus with decreased CSF turnover is suggested to have no efficacy.

\section{Shunt valve selection}

\section{CQ-11. Which type of CSF shunt should be utilized in treating iNPH?}

A programmable-pressure valve is recommended. If intracranial hypotension is detected, a mechanism (anti-siphon/gravity device, etc.) to prevent excessive drainage should be added.

Recommendation Grade 1, Level of Evidence B

(1) "Fixed" vs. "programmable" pressure valves

The fixed pressure valve has the advantage of having a simple mechanism and lower cost. However, when the flow rate is too high or low, the valve needs to be replaced. In a comparison of the fixed-pressure and programmable-pressure valves used in communicating hydrocephalus, including iNPH, up to the 2000s, the shunt revision rate and incidence rates of subdural effusion and hematoma remained the same between the two types of valves. ${ }^{232,233)} \mathrm{A}$ meta-analysis comparing fixed-pressure and programmable-pressure valves in 1702 hydrocephalus patients over the age of 16 years in seven studies showed no significant differences in catheter-related complications or infection rate. However, with the programmable-pressure valve, over- or under-drainage and shunt revision rates were significantly higher. ${ }^{234)}$ A meta-analysis of hydrocephalus patients, including 2,622 children, showed no significant differences between the fixed-pressure and programmable-pressure groups regarding shunt survival rate and overall complications at 1 year. However, the shunt revision rate and over- and under-drainage rates were significantly lower in the variable pressure group. The programmable-pressure valves were reported to be particularly useful for adult patients 18 years and older. ${ }^{235)}$ In a meta-analysis of 33 studies on iNPH patients published in 2018, the rate of symptomatic improvement was unchanged ( $76 \%$ vs. $74 \%)$ when the fixed-pressure and programmable-pressure types were compared. However, subdural fluid retention ( $9 \%$ vs. $12 \%)$ and reconstruction rates $(12 \%$ vs. $32 \%)$ were reported to be significantly higher in the fixed pressure valve. ${ }^{236)}$ In terms of cost, a retrospective examination of 110 tap-positive iNPH patients revealed that many patients required shunt revision and surgery for a subdural hematoma in the fixed-pressure group. The cost of addressing the complications that arise with the use of the fixed-pressure valve was estimated to be offset using programmable-pressure valves. ${ }^{237}$

Selecting a programmable-pressure valve for iNPH patients is recommended because the pressure can be set flexibly according to the patient's activities of daily living and symptoms.

(2) "With" vs. "without" over-drainage prevention mechanisms

In recent years, additional mechanisms (antisiphon/gravity device, etc.) have resulted in less subdural CSF collections and hematomas than are seen with a programmable-pressure valve that has been adjusted to low pressure, and management is more uniform. These findings have been observed in $\operatorname{RCTs}^{238,239)}$ and observational studies. ${ }^{240-243)}$ However, it is challenging for single valve groups to be compared, and in a comparison of the SINPHONI (VP shunt using single programmablepressure valve) and SINPHONI-2 (LP shunt using programmable-pressure valve with siphon-guard system) studies in Japan, no differences were seen in the frequency of subdural effusion and hematoma. ${ }^{8)}$ Therefore, using an over-drainage prevention mechanism is not indispensable unless low pressure is set from the beginning. Even in a meta-analysis that compared shunt valves, no significant difference was observed in the symptom improvement rate, subdural fluid retention rate, and shunt revision rate between the single programmable-pressure valve with and without an over-drainage prevention mechanism. ${ }^{236)}$

(3) "Pressure" vs. "Flow" regulated valves

As another valve mechanism, the flow-regulated control valve is hardly used because the flow rate may be affected by the position in which the valve is implanted and subcutaneous tissue pressure. ${ }^{244)}$ Comparisons between flow control valves and fixed pressure valves reported no differences in the rates of symptom improvement, infection, shunt malfunction, and subdural effusion. ${ }^{245,246)}$ Since programmable- pressure valves can be used, the significance of flow-regulated system is low at present. 


\section{Shunt complications}

\section{CQ-12. What strategies are available for minimizing the complications of shunt placement?}

Some complications can be avoided by preparing and planning preoperatively, and paying attention to shunt malfunction after the shunt intervention, excessive drainage of CSF, and shunt infection.

Recommendation Grade 1, Level of Evidence C

Complications of shunt intervention include shunt dysfunction due to obstruction of the shunt tube, headache, shunt infection, and subdural hematoma, which is associated with over-drainage of CSF after the shunt intervention. ${ }^{238}$

\section{Appropriate catheter placement}

As the most important factor in shunt malfunction, it is necessary to pay special attention to proper cerebral ventricle puncture and catheter placement in VP and VA shunts. ${ }^{247-250)}$ For cerebral ventricular puncture, equivalent reliability has been reported for frontal horn (frontal approach) and occipital horn/trigonum punctures (parieto-occipital approach). In both cases, the procedure should not be performed by free-hand puncture, and the puncture point should be examined based on the preoperative imaging. ${ }^{251)}$ Imaging guides such as neuro-navigation and stereotaxy are useful for placing the cerebral ventricle catheters in proper position without interfering with structures such as the ventricular wall and choroid plexus. ${ }^{247,248,252-254)}$

On the other hand, LP shunts have the advantage of not involving the risk of causing intracerebral hemorrhage because they are not directly invasive to the brain parenchyma like VP shunts. However, in the elderly who are potential iNPH patients, because spinal degenerative disease occurs frequently, diagnostic imaging of the entire spine should be done before surgery, and attention should be paid to shunt malfunction due to obstruction or rupture of the lumbar catheter. Placement of a lumbar catheter in the proper position by fluoroscopy-guided paramedian lumbar puncture increases safety and accuracy. ${ }^{255-256)}$ Besides, to prevent the tube from protruding out of the abdominal cavity, it is necessary to perform an insertion technique that eliminates all spaces through which the tube can potentially protrude or migrate under the skin. ${ }^{8,257)}$

\section{Preventing shunt infection}

Infection of the shunt system is an important surgical complication that is directly related to further severe complications such as meningitis and peritoneal infection. A protocol should be devised that includes the following: patients should be put on antibiotics before the skin incision, double gloves should be worn during the procedure, the shunt device should be immersed in saline with antibiotics to minimize contamination from air, and antibiotics also should be injected locally into the surgical wound. These precautions have been reported as effective in preventing shunt infection not only in pediatric cases but also in adults aged 40-88 years (average 59 years). ${ }^{258)}$ Also, there have been reports stating that the use of antibiotic-impregnated catheters (AICs) has reduced shunt infection rate in pediatric patients. ${ }^{259,260)}$ Additionally, reports have asserted that shunt infection is significantly suppressed in NPH patients other than those with iNPH. ${ }^{261)}$ However, in patients for whom AICs are indicated, the risk of growth of resistant bacteria should be considered, and AICs should only be used as required.

\section{Chapter 5. Postoperative Management and Prognosis}

\section{Initial valve pressure setting}

\section{CQ-13. How should the initial pressure settings of programmable-pressure valves be configured in iNPH patients?}

Initial high pressure setting with gradual decrease until clinical response or over-drainage symptoms are observed can be the proper approach. An alternative can be setting initial pressure according to the body height and weight/gender table and implementing corrections if necessary.

Recommendation Grade 2, Level of Evidence C

The initial pressure setting method can be any of the following:

(1) Start from high pressure and gradually lower it while observing the symptoms to find the optimal pressure setting.

(2) Start from the pressure that is considered adequate for each patient based on the various parameters.

(3) Start from a certain fixed pressure (such as $12 \mathrm{cmH}_{2} \mathrm{O}$ ).

(4) Start from the low pressure setting and gradually increase it while monitoring the symptoms to find the optimal pressure setting.

In a prospective, double-blind study using a Codman-Hakim programmable-pressure valve (CHPV, Integra), the subjects were divided into a group in which the valve pressure was started at $20 \mathrm{cmH}_{2} \mathrm{O}$ and decreased gradually by $4 \mathrm{cmH}_{2} \mathrm{O}$ each month, and another group in which the pressure was fixed at $12 \mathrm{cmH}_{2} \mathrm{O}$. The clinical symptoms were then 
evaluated after 6 months. ${ }^{262,263)}$ There were no differences in efficacy between the two groups, and no further improvement was observed even when the pressure was reduced to below $12 \mathrm{cmH}_{2} \mathrm{O}$.

Therefore, initially setting the pressure at 12 $\mathrm{cmH}_{2} \mathrm{O}$ is adequate. However, in the fixed-pressure valve group, nine patients exhibited over-drainage (9/34), four of which dropped out in the latter half of the study. In another study that used the Strata valve (Medtronic, Minneapolis, MN, USA), comparison was also made between a group in which the valve pressure was fixed at performance level (PL) 1.0, and another group in which the pressure was started at PL 2.5 and gradually decreased until symptoms improved or over-drainage symptoms appeared. It was reported that over-drainage complications were more common in the former group. ${ }^{239)}$

In minimizing the incidence of over-drainage, the initial pressure setting method (1) is superior. However, adjustment from the high pressure setting requires multiple changes to the optimal pressure setting and takes time. Additionally, although the level of improvement was the same between the two groups with no significant difference, it should be noted that there seemed to be a delay in symptom improvement. For method (2), various CSF dynamic tests such as Rout and a method for estimating the set pressure based on ICP have been reported. ${ }^{264-266)}$ On the other hand, using the quantitative initial pressure setting method in a sitting position, ${ }^{267)}$ a quick reference table shows that for estimating the initial pressure based on height and weight (Table 4), both the number of changes and the range of the setting change are smaller than those of the methods described above. ${ }^{268-270)}$ This method, which is based on a sitting position with a large siphon effect, inevitably results in a higher setting. The initial pressure setting according to the quick reference table was adapted in the SINPHONI study for the patients treated with VP shunt surgery using $\mathrm{CHPV}^{4)}$ and in SINPHONI-2 study for the patients treated with LP shunt surgery using CHPV plus siphon-guard. ${ }^{7)}$ The usefulness and safety of the initial pressure setting were confirmed in these studies.

\section{Prognosis after shunt surgery}

\section{$C Q-14$. What are the short-term and long-term outcomes of iNPH, and what degree of improve- ment can be expected for each symptom?}

Symptoms usually improve after surgical intervention. However, the short-term outcomes are affected by postoperative complication, disease duration, severity of disease, tap test response, and typical imaging findings of DESH. The longterm outcomes are affected by the presence of any comorbidity. The degree of improvement in gait disturbance is the highest, followed by cognitive impairment and urinary dysfunction.

\section{Recommendation Grade 2, Level of Evidence C}

Outcomes after surgical treatment have been reported for varying periods, from 3 months to 6 years. ${ }^{4,7,271-274)}$ Based on evaluations such as mRS, improvement rate after shunt intervention is reported to be approximately $39-81 \%$ in $3-6$ months, $, 7,271,272)$ $63-84 \%$ in 1 year, ${ }^{4,7,273)} 69 \%$ in 2 years, ${ }^{274)}$ and approximately $60-74 \%$ in 3-6 years. ${ }^{275)}$ However, in these studies, some of the subjects did not meet the diagnostic criteria stipulated in the Japanese and international guidelines, and sNPH patients may have been included.

Regarding the rate of improvement in symptoms after shunt interventions, gait disturbance showed the highest rate of improvement, and although the evaluation methods varied, it is reported to be approximately $60-77 \% .{ }^{273,276,277)}$ Even for cognitive impairment, the evaluation methods varied; however, the improvement rate is reported to be $61-69 \% .{ }^{274,277,278)}$ Regarding urinary incontinence, an improvement rate of $52 \%$ has been reported. ${ }^{276)}$ Although shunt interventions have been recognized to have a certain beneficial effect, the extent of their stated effectiveness varies. Moreover, the diagnosis of iNPH, modality of shunt intervention, symptom evaluation method, and criteria for assessing improvement can notably differ depending on the study. Short-term outcomes (at 1 year after shunt interventions) may be affected by complications related to the surgical procedure. Furthermore, results are also affected by the duration and severity of disease, response to tap test, and the status of typical imaging findings (DESH). ${ }^{180,183,279)}$

The long-term outcomes are more affected by comorbidities. For example, stroke affects functional prognosis, cancer affects life prognosis, Alzheimer's disease affects cognitive function, and Parkinson's disease affects motor function. ${ }^{208,274,280)}$ All of these can notably affect the long-term outcomes of a shunt intervention. It is therefore good to predict the coexistence of comorbidities, such as Alzheimer's disease, using biomarkers before surgery. ${ }^{272,274,280)}$ Moreover, if the outcome can be predicted clinically using the frailty index or the comorbidity index, this can be useful for deciding which surgical modality will result in good postsurgical outcome. ${ }^{281,282)}$ If the Kiefer comorbidity index is 3 points or less, improvement rate following a shunt intervention is $93 \%$ after 2 years. If it is more than 4 points, 


\begin{tabular}{|c|c|c|c|c|c|c|c|c|c|c|c|c|c|c|c|c|c|}
\hline Women & & & & & & & & & BW $(\mathrm{kg}$ & & & & & & & & \\
\hline $\mathrm{Ht}(\mathrm{cm})$ & 35 & 40 & 45 & 50 & 55 & 60 & 65 & 70 & 75 & 80 & 85 & 90 & 95 & & 100 & 105 & 110 \\
\hline 140 & 16 & 12 & 9 & 6 & 3 & & & & & & & & & & & & \\
\hline 145 & 19 & 16 & 13 & 10 & 7 & 4 & & & & & & & & & & & \\
\hline 150 & 23 & 19 & 16 & 13 & 10 & 7 & 4 & & & & & & & & & & \\
\hline 155 & 26 & 23 & 20 & 17 & 14 & 12 & 9 & 6 & 3 & & & & & & & & \\
\hline 160 & 29 & 27 & 24 & 21 & 18 & 16 & 13 & 11 & 8 & 5 & 3 & & & & & & \\
\hline 165 & 33 & 30 & 27 & 24 & 21 & 18 & 16 & 14 & 12 & 10 & 8 & 5 & 1 & & & & \\
\hline 170 & 36 & 34 & 31 & 28 & 25 & 23 & 20 & 18 & 15 & 13 & 11 & 9 & 6 & & 4 & & \\
\hline 175 & 39 & 37 & 34 & 31 & 29 & 27 & 24 & 20 & 18 & 16 & 14 & 12 & 10 & & 8 & 5 & 3 \\
\hline 180 & 42 & 40 & 37 & 35 & 33 & 31 & 28 & 26 & 23 & 20 & 18 & 16 & 14 & & 12 & 10 & 8 \\
\hline Men & & & & & & & & & BW $(\mathrm{kg}$ & & & & & & & & \\
\hline $\mathrm{Ht}(\mathrm{cm})$ & 35 & 40 & 45 & 50 & 55 & & 60 & 65 & 70 & 75 & 80 & 85 & 90 & 95 & 100 & 105 & 110 \\
\hline 145 & 20 & 18 & 15 & 12 & 9 & & 6 & 3 & & & & & & & & & \\
\hline 150 & 23 & 20 & 18 & 15 & 12 & & 9 & 6 & & & & & & & & & \\
\hline 155 & 26 & 23 & 21 & 19 & 16 & & 14 & 11 & 8 & 5 & 3 & & & & & & \\
\hline 160 & 29 & 27 & 24 & 21 & 19 & & 17 & 14 & 12 & 9 & 6 & 4 & 1 & & & & \\
\hline 165 & 32 & 30 & 27 & 24 & 22 & & 20 & 18 & 16 & 14 & 11 & 8 & 6 & 4 & 1 & & \\
\hline 170 & 35 & 33 & 31 & 28 & 25 & & 23 & 21 & 19 & 16 & 14 & 12 & 10 & 7 & 5 & 2 & \\
\hline 175 & 38 & 36 & 34 & 31 & 29 & & 27 & 25 & 23 & 21 & 18 & 16 & 14 & 12 & 10 & 7 & 5 \\
\hline 180 & 41 & 39 & 37 & 34 & 32 & & 30 & 28 & 25 & 23 & 21 & 19 & 17 & 15 & 13 & 11 & 9 \\
\hline
\end{tabular}

All quick reference table values are shown in $\mathrm{cmH}_{2} \mathrm{O} . \mathrm{BW}$ : body weight, Ht: height. (Revised from ref. 270). 
the improvement rate is low, and no improvement can be expected if it is 6 points or more. ${ }^{2811}$ However, this index does not include cognitive impairment, such as Alzheimer's disease, which is a major component of iNPH comorbidity.

Evaluations of gait disturbance, cognitive impairment, and urinary dysfunction after shunt interventions have been performed using various scales that were either specific or not specific (e.g., mRS) to iNPH. Therefore, it is difficult to compare studies using various scales, and the development of a simpler, common evaluation method that can sensitively detect the effects of shunt interventions is awaited. For the time being, it will be better to evaluate the application of iNPHGS instead of assessing only the degree of independence with mRS.

\section{Shunt surgery cost-effectiveness}

\section{CQ-15. Is shunt placement for iNPH effective from a healthcare cost-effectiveness perspective?}

Shunt intervention for iNPH is medically and economically effective.

\section{Recommendation Grade 2, Level of Evidence B}

iNPH is a syndrome that causes gait disturbance, dementia, and urinary incontinence that can be improved with standard CSF shunt intervention; that is, iNPH is a treatable disease. Therefore, several studies have been conducted on shunt interventions from the viewpoint of medical economics. ${ }^{283-286)}$

The economic effects based on the results of the SINPHONI and SINPHONI-2 studies reported that the incremental cost-effectiveness ratio 1 year after shunt intervention was 29934-40742 USD/quality-adjusted life year (QALY) for the VP shunt, and 58346-80392 USD/QALY for the LP shunt. ${ }^{285)}$ Moreover, the cost (sum of surgical cost and nursing care cost) of iNPH treatments was estimated to reduce 18 months after VP shunt surgery and 21 months after LP shunt surgery, compared to the cost of nursing care in untreated iNPH patients. The economic effects of iNPH treatment were also studied with the Markov model based on data from 30 Swedish iNPH patients. The study reported that an additional lifetime of 2.2 years and 1.7 QALY was gained with treatment, with an additional cost of $€ 13,000 .{ }^{286}$ )

\section{Conclusion}

Almost 15 years have passed since the first edition of the Japanese guidelines for iNPH management was published in 2004. In the meantime, the recognition of iNPH has significantly increased, and it is no exaggeration to say that the diagnosis and treatment of iNPH have entered a new phase. We hope that this third edition of the guidelines will further refine the diagnosis and treatment of iNPH, and help patients, their families, and healthcare professionals involved in treating the condition.

\section{Acknowledgments}

We thank Dr. Kostadin Karagiozov for editing the manuscript. This work is supported by the Ministry of Health, Labour and Welfare of Japan Sciences Research Grants Subsidy for Intractable Diseases Policy Research Project (2017-Nanchi-General-037).

\section{Conflicts of Interest Disclosure}

The committee paid for expenses such as meeting venues and transportation for attending the committee meetings. The committee did not pay an honorarium to the committee members or study collaborators for writing manuscripts or participating in meetings.

The present guidelines have been prepared based on appropriate conflict of interest (COI) management by the operating rules of the Japan Neurosurgical Society, the Japanese Society of Neurology, the Japanese Society of Psychiatry and Neurology, and the Japan Radiological Society. The committee members, study collaborators, and evaluation/ coordinating committee members involved in these guidelines submitted self-reports to their respective academic societies regarding their COIs for the past 3 years based on the standards set by the academic societies to which they belong.

Honorarium for executives, stocks, patent royalties, lecture fees, manuscript fees, research expenses, subsidies, travel expenses, gifts, scholarships (encouragements) endowment, affiliation with an endowed chair.

Moreover, all organizations such as corporations targeted for the declaration are all "corporations/ corporate organizations related to medical research and organizations for profit-making purposes." After being reviewed by the COI Review Committee, the Guidelines were prepared/revised according to the results of the review.

The companies declared in the COI are shown below:

Actelion Pharmaceuticals Japan Ltd., Idorsia Pharmaceuticals Japan Ltd., Eisai Co., Ltd., Kaneka Medix Corporation, Software Service, Inc., Terumo Corporation, Sumitomo Dainippon Pharma, Mitsubishi Tanabe Pharma, Stryker Japan, Nippontectsystems co., Ltd., Nihon Medi-Physics Co., Ltd., Medtronic Japan Co., Ltd., Hitachi, Ltd., Fujitsu Limited, FUJIFILM Corporation, Heptares Therapeutics Ltd., Integra Japan, Mentis Cura Japan, PMOD Inc. 


\section{References}

1) Hakim $S$, Adams RD: The special clinical problem of symptomatic hydrocephalus with normal cerebrospinal fluid pressure. Observations on cerebrospinal fluid hydrodynamics. J Neurol Sci 2: 307-327, 1965

2) Adams RD, Fisher CM, Hakim S, Ojemann RG, Sweet WH: Symptomatic occult hydrocephalus with "normal" cerebrospinal-fluid pressure. A treatable syndrome. N Engl J Med 273: 117-126, 1965

3) Ishikawa $M$ : Guideline Committe for Idiopathic Normal Pressure Hydrocephalus, Japanese Society of Normal Pressure Hydrocephalus: Clinical guidelines for idiopathic normal pressure hydrocephalus. Neurol Med Chir (Tokyo) 44: 222-223, 2004

4) Hashimoto M, Ishikawa M, Mori E, Kuwana N: Study of INPH on neurological improvement (SINPHONI): Diagnosis of idiopathic normal pressure hydrocephalus is supported by MRI-based scheme: a prospective cohort study. Cerebrospinal Fluid Res 7: 18, 2010

5) Kitagaki H, Mori E, Ishii K, Yamaji S, Hirono N, Imamura T: CSF spaces in idiopathic normal pressure hydrocephalus: morphology and volumetry. AJNR Am J Neuroradiol 19: 1277-1284, 1998

6) Mori E, Ishikawa M, Kato T, et al.: Guidelines for management of idiopathic normal pressure hydrocephalus: second edition. Neurol Med Chir (Tokyo) 52: 775-809, 2012

7) Kazui H, Miyajima M, Mori E, Ishikawa M: SINPHONI-2 Investigators: Lumboperitoneal shunt surgery for idiopathic normal pressure hydrocephalus (SINPHONI-2): an open-label randomised trial. Lancet Neurol 14: 585-594, 2015

8) Miyajima M, Kazui H, Mori E, Ishikawa M: on behalf of the SINPHONI-2 Investigators: One-year outcome in patients with idiopathic normal-pressure hydrocephalus: comparison of lumboperitoneal shunt to ventriculoperitoneal shunt. J Neurosurg 125: 1483-1492, 2016

9) Kuriyama N, Miyajima M, Nakajima M, et al.: Nationwide hospital-based survey of idiopathic normal pressure hydrocephalus in Japan: epidemiological and clinical characteristics. Brain Behav 7: e00635, 2017

10) Nakajima M, Miyajima M, Ogino I, et al.: Shunt Intervention for possible idiopathic normal pressure hydrocephalus improves patient outcomes: a nationwide hospital-based survey in Japan. Front Neurol 9: 421, 2018

11) Relkin N, Marmarou A, Klinge P, Bergsneider M, Black PM: Diagnosing idiopathic normal-pressure hydrocephalus. Neurosurgery 57: S4-S16, 2005

12) Wilson RK, Williams MA: Evidence that congenital hydrocephalus is a precursor to idiopathic normal pressure hydrocephalus in only a subset of patients. J Neurol Neurosurg Psychiatry 78: 508-511, 2007

13) Marmarou A, Young HF, Aygok GA, et al.: Diagnosis and management of idiopathic normal-pressure hydrocephalus: a prospective study in 151 patients. J Neurosurg 102: 987-997, 2005
14) Woodworth GF, McGirt MJ, Williams MA, Rigamonti D: Cerebrospinal fluid drainage and dynamics in the diagnosis of normal pressure hydrocephalus. Neurosurgery 64: 919-925; discussion 925-926, 2009

15) Oi S, Shimoda M, Shibata M, et al.: Pathophysiology of long-standing overt ventriculomegaly in adults. J Neurosurg 92: 933-940, 2000

16) Cornips EMJ, Overvliet GM, Weber JW, et al.: The clinical spectrum of Blake's pouch cyst: report of six illustrative cases. Childs Nerv Syst 26: 1057-1064, 2010

17) Gangemi M, Maiuri F, Naddeo M, et al.: Endoscopic third ventriculostomy in idiopathic normal pressure hydrocephalus: an Italian multicenter study. Neurosurgery 63: 62-67; discussion 67-69, 2008

18) Fukuhara T, Luciano MG: Clinical features of late-onset idiopathic aqueductal stenosis. Surg Neurol 55: 132-136; discussion 136-137, 2001

19) Takahashi $Y$, Kawanami T, Nagasawa H, Iseki $C$, Hanyu H, Kato T: Familial normal pressure hydrocephalus (NPH) with an autosomal-dominant inheritance: a novel subgroup of NPH. J Neurol Sci 308: 149-151, 2011

20) McGirr A, Cusimano MD: Familial aggregation of idiopathic normal pressure hydrocephalus: novel familial case and a family study of the NPH triad in an iNPH patient cohort. J Neurol Sci 321: 82-88, 2012

21) Huovinen J, Kastinen S, Komulainen S, et al.: Familial idiopathic normal pressure hydrocephalus. J Neurol Sci 368: 11-18, 2016

22) Hiraoka K, Meguro K, Mori E: Prevalence of idiopathic normal-pressure hydrocephalus in the elderly population of a Japanese rural community. Neurol Med Chir (Tokyo) 48: 197-199; discussion 199-200, 2008

23) Tanaka N, Yamaguchi S, Ishikawa H, Ishii H, Meguro K: Prevalence of possible idiopathic normal-pressure hydrocephalus in Japan: the Osaki-Tajiri project. Neuroepidemiology 32: 171-175, 2009

24) Iseki C, Kawanami T, Nagasawa H, et al.: Asymptomatic ventriculomegaly with features of idiopathic normal pressure hydrocephalus on MRI (AVIM) in the elderly: a prospective study in a Japanese population. J Neurol Sci 277: 54-57, 2009

25) Iseki C, Takahashi Y, Wada M, Kawanami T, Adachi M, Kato T: Incidence of idiopathic normal pressure hydrocephalus (iNPH): a 10-year follow-up study of a rural community in Japan. J Neurol Sci 339: 108-112, 2014

26) Nakashita S, Wada-Isoe K, Uemura Y, et al.: Clinical assessment and prevalence of parkinsonism in Japanese elderly people. Acta Neurol Scand 133: 373379, 2016

27) Andersson J, Rosell M, Kockum K, Lilja-Lund O, Söderström L, Laurell K: Prevalence of idiopathic normal pressure hydrocephalus: a prospective, population-based study. PLoS One 14: e0217705, 2019

28) Jaraj D, Rabiei K, Marlow T, Jensen C, Skoog I, Wikkelsø C: Prevalence of idiopathic normal-pressure hydrocephalus. Neurology 82: 1449-1454, 2014 
29) Vanneste J, Augustijn P, Dirven C, Tan WF, Goedhart ZD: Shunting normal-pressure hydrocephalus: do the benefits outweigh the risks? A multicenter study and literature review. Neurology 42: 54-59, 1992

30) Tisell M, Höglund M, Wikkelsø C: National and regional incidence of surgery for adult hydrocephalus in Sweden. Acta Neurol Scand 112: 72-75, 2005

31) Brean A, Fredø HL, Sollid S, Müller T, Sundstrøm T, Eide PK: Five-year incidence of surgery for idiopathic normal pressure hydrocephalus in Norway. Acta Neurol Scand 120: 314-316, 2009

32) Klassen BT, Ahlskog JE: Normal pressure hydrocephalus: how often does the diagnosis hold water? Neurology 77: 1119-1125, 2011

33) Muangpaisan W, Petcharat C, Srinonprasert V: Prevalence of potentially reversible conditions in dementia and mild cognitive impairment in a geriatric clinic. Geriatr Gerontol Int 12: 59-64, 2012

34) Trenkwalder C, Schwarz J, Gebhard J, et al.: Starnberg trial on epidemiology of Parkinsonism and hypertension in the elderly. Prevalence of Parkinson's disease and related disorders assessed by a door-to-door survey of inhabitants older than 65 years. Arch Neurol 52: 1017-1022, 1995

35) Bech-Azeddine R, Waldemar G, Knudsen GM, et al.: Idiopathic normal-pressure hydrocephalus: evaluation and findings in a multidisciplinary memory clinic. Eur J Neurol 8: 601-611, 2001

36) Isaacs AM, Riva-Cambrin J, Yavin D, et al.: Age-specific global epidemiology of hydrocephalus: systematic review, metanalysis and global birth surveillance. PLoS One 13: e0204926, 2018

37) Black PM: Idiopathic normal-pressure hydrocephalus. Results of shunting in 62 patients. J Neurosurg 52: 371-377, 1980

38) Marmarou A, Bergsneider M, Relkin N, Klinge P, Black PM: Development of guidelines for idiopathic normal-pressure hydrocephalus: introduction. Neurosurgery 57: S1-3; discussion ii-v, 2005

39) Miyoshi N, Kazui H, Ogino A, Ishikawa M, Miyake H, Tokunaga H, Ikejiri Y, Takeda M: Association between cognitive impairment and gait disturbance in patients with idiopathic normal pressure hydrocephalus. Dement Geriatr Cogn Disord 20: 71-76, 2005

40) Stolze H, Kuhtz-Buschbeck JP, Drücke H, et al.: Gait analysis in idiopathic normal pressure hydrocephalus--which parameters respond to the CSF tap test? Clin Neurophysiol 111: 1678-1686, 2000

41) Stolze H, Kuhtz-Buschbeck JP, Drücke H, Jöhnk K, Illert M, Deuschl G: Comparative analysis of the gait disorder of normal pressure hydrocephalus and Parkinson's disease. J Neurol Neurosurg Psychiatry 70: 289-297, 2001

42) Williams MA, Thomas G, de Lateur B, et al.: Objective assessment of gait in normal-pressure hydrocephalus. Am J Phys Med Rehabil 87: 39-45, 2008

43) Bugalho P, Alves L: Normal-pressure hydrocephalus: white matter lesions correlate negatively with gait improvement after lumbar puncture. Clin Neurol Neurosurg 109: 774-778, 2007
44) Marmarou A, Young HF, Aygok GA, et al.: Diagnosis and management of idiopathic normal-pressure hydrocephalus: a prospective study in 151 patients. $J$ Neurosurg 102: 987-997, 2005

45) Solana E, Poca MA, Sahuquillo J, Benejam B, Junqué C, Dronavalli M: Cognitive and motor improvement after retesting in normal-pressure hydrocephalus: a real change or merely a learning effect? J Neurosurg 112: 399-409, 2010

46) Kubo Y, Kazui H, Yoshida T, et al.: Validation of grading scale for evaluating symptoms of idiopathic normal-pressure hydrocephalus. Dement Geriatr Cogn Disord 25: 37-45, 2008

47) Podsiadlo D, Richardson S: The timed "Up \& Go": a test of basic functional mobility for frail elderly persons. J Am Geriatr Soc 39: 142-148, 1991

48) Nakayama T, Ouchi Y, Yoshikawa E, Sugihara G, Torizuka T, Tanaka K: Striatal D2 receptor availability after shunting in idiopathic normal pressure hydrocephalus. J Nucl Med 48: 1981-1986, 2007

49) Hattingen E, Jurcoane A, Melber J, et al.: Diffusion tensor imaging in patients with adult chronic idiopathic hydrocephalus. Neurosurgery 66: 917-924, 2010

50) Iddon JL, Morgan DJ, Loveday C, Sahakian BJ, Pickard JD: Neuropsychological profile of young adults with spina bifida with or without hydrocephalus. J Neurol Neurosurg Psychiatry 75: 1112-1118, 2004

51) Boon AJ, Tans JT, Delwel EJ, et al.: Dutch normal-pressure hydrocephalus study: prediction of outcome after shunting by resistance to outflow of cerebrospinal fluid. J Neurosurg 87: 687-693, 1997

52) Chaudhry P, Kharkar S, Heidler-Gary J, et al.: Characteristics and reversibility of dementia in normal pressure hydrocephalus. Behav Neurol 18: 149-158, 2007

53) Ogino A, Kazui H, Miyoshi N, et al.: Cognitive impairment in patients with idiopathic normal pressure hydrocephalus. Dement Geriatr Cogn Disord 21: 113119, 2006

54) Thomas G, McGirt MJ, Woodworth G, et al.: Baseline neuropsychological profile and cognitive response to cerebrospinal fluid shunting for idiopathic normal pressure hydrocephalus. Dement Geriatr Cogn Disord 20: 163-168, 2005

55) Hellström P, Edsbagge M, Archer T, Tisell M, Tullberg M, Wikkelsø C: The neuropsychology of patients with clinically diagnosed idiopathic normal pressure hydrocephalus. Neurosurgery 61: 1219-1226; discussion 1227-1228, 2007

56) Akiguchi I, Ishii M, Watanabe Y, et al.: Shunt-responsive parkinsonism and reversible white matter lesions in patients with idiopathic NPH. J Neurol 255: 1392-1399, 2008

57) Mataró M, Matarín M, Poca MA, et al.: Functional and magnetic resonance imaging correlates of corpus callosum in normal pressure hydrocephalus before and after shunting. J Neurol Neurosurg Psychiatry 78: 395-398, 2007

58) del Mar Matarin M, Pueyo R, Poca MA, et al.: Postsurgical changes in brain metabolism detected by magnetic resonance spectroscopy in normal pressure 
hydrocephalus: results of a pilot study. J Neurol Neurosurg Psychiatry 78: 760-763, 2007

59) Krauss JK, Droste DW, Vach W, et al.: Cerebrospinal fluid shunting in idiopathic normal-pressure hydrocephalus of the elderly: effect of periventricular and deep white matter lesions. Neurosurgery 39: 292-299; discussion 299-300, 1996

60) Mori K: Management of idiopathic normal-pressure hydrocephalus: a multiinstitutional study conducted in Japan. J Neurosurg 95: 970-973, 2001

61) Kristensen B, Malm J, Fagerland M, et al.: Regional cerebral blood flow, white matter abnormalities, and cerebrospinal fluid hydrodynamics in patients with idiopathic adult hydrocephalus syndrome. J Neurol Neurosurg Psychiatry 60: 282-288, 1996

62) Raftopoulos C, Deleval J, Chaskis C, et al.: Cognitive recovery in idiopathic normal pressure hydrocephalus: a prospective study. Neurosurgery 35: 397-404; discussion 404-395, 1994

63) Walchenbach R, Geiger E, Thomeer RT, Vanneste JA: The value of temporary external lumbar CSF drainage in predicting the outcome of shunting on normal pressure hydrocephalus. J Neurol Neurosurg Psychiatry 72: 503-506, 2002

64) Folstein MF, Folstein SE, McHugh PR: Mini-mental state". A practical method for grading the cognitive state of patients for the clinician. J Psychiatr Res 12: 189-198, 1975

65) Dubois B, Slachevsky A, Litvan I, Pillon B: The FAB: a Frontal Assessment Battery at bedside. Neurology 55: 1621-1626, 2000

66) Pilgrim BM, Meyers JE, Bayless J, Whetstone MM: Validity of the Ward seven-subtest WAIS-III short form in a neuropsychological population. Appl Neuropsychol 6: 243-246, 1999

67) Wilson B, Cockburn J, Baddeley A, Hiorns R: The development and validation of a test battery for detecting and monitoring everyday memory problems. J Clin Exp Neuropsychol 11: 855-870, 1989

68) Kazui H, Matsuda A, Hirono N, et al.: Everyday memory impairment of patients with mild cognitive impairment. Dement Geriatr Cogn Disord 19: 331337, 2005

69) Hellström P, Klinge P, Tans J, Wikkelsø C: The neuropsychology of iNPH: findings and evaluation of tests in the European multicentre study. Clin Neurol Neurosurg 114: 130-134, 2012

70) Mathew R, Pavithran S, Byju P: Neuropsychiatric manifestations of cognitively advanced idiopathic normal pressure hydrocephalus. Dement Geriatr Cogn Dis Extra 8: 467-475, 2018

71) Kito Y, Kazui H, Kubo Y, et al.: Neuropsychiatric symptoms in patients with idiopathic normal pressure hydrocephalus. Behav Neurol 21: 165-174, 2009

72) Kanemoto H, Kazui H, Suzuki Y, et al.: Effect of lumbo-peritoneal shunt surgery on neuropsychiatric symptoms in patients with idiopathic normal pressure hydrocephalus. J Neurol Sci 361: 206-212, 2016

73) Kanemoto H, Kazui H, Suehiro T, et al.: Apathy and right caudate perfusion in idiopathic normal pressure hydrocephalus: a case-control study. Int J Geriatr Psychiatry 34: 453-462, 2019

74) Allali G, Laidet M, Armand S, Saj A, Krack P, Assal F: Apathy in idiopathic normal pressure hydrocephalus: a marker of reversible gait disorders. Int $J$ Geriatr Psychiatry 33: 735-742, 2018

75) Allali G, Laidet M, Armand S, Saj A, Krack P, Assal F: Apathy and higher level of gait control in normal pressure hydrocephalus. Int J Psychophysiol 119: 127-131, 2017

76) Krzastek SC, Bruch WM, Robinson SP, Young HF, Klausner AP: Characterization of lower urinary tract symptoms in patients with idiopathic normal pressure hydrocephalus. Neurourol Urodyn 36: 11671173, 2017

77) Campos-Juanatey F, Gutiérrez-Baños JL, PortilloMartín JA, Zubillaga-Guerrero S: Assessment of the urodynamic diagnosis in patients with urinary incontinence associated with normal pressure hydrocephalus. Neurourol Urodyn 34: 465-468, 2015

78) Sakakibara R, Kanda T, Sekido T, et al.: Mechanism of bladder dysfunction in idiopathic normal pressure hydrocephalus. Neurourol Urodyn 27: 507-510, 2008

79) Skelly J, Flint AJ: Urinary incontinence associated with dementia. J Am Geriatr Soc 43: 286-294, 1995

80) Yap P, Tan D: Urinary incontinence in dementia - a practical approach. Aust Fam Physician 35: 237-241, 2006

81) Factora R, Luciano M: Normal pressure hydrocephalus: diagnosis and new approaches to treatment. Clin Geriatr Med 22: 645-657, 2006

82) Pomeraniec IJ, Ksendzovsky A, Ellis S, Roberts SE, Jane JA: Frequency and long-term follow-up of trapped fourth ventricle following neonatal posthemorrhagic hydrocephalus. J Neurosurg Pediatr 17: 552-557, 2016

83) Larsson A, Wikkelsö C, Bilting M, Stephensen H: Clinical parameters in 74 consecutive patients shunt operated for normal pressure hydrocephalus. Acta Neurol Scand 84: 475-482, 1991

84) Krauss JK, Regel JP, Droste DW, Orszagh M, Borremans JJ, Vach W: Movement disorders in adult hydrocephalus. Mov Disord 12: 53-60, 1997

85) Nowak DA, Topka HR: Broadening a classic clinical triad: the hypokinetic motor disorder of normal pressure hydrocephalus also affects the hand. Exp Neurol 198: 81-87, 2006

86) Nowak DA, Gumprecht H, Topka H: CSF drainage ameliorates the motor deficit in normal pressure hydrocephalus: evidence from the analysis of grasping movements. J Neurol 253: 640-647, 2006

87) Odagiri H, Baba T, Nishio Y, Iizuka O, Narita W, Matsuda M, Mori E: Clinical characteristics of idiopathic normal pressure hydrocephalus with Lewy body diseases. J Neurol Sci 359: 309-311, 2015

88) Sasaki M, Honda S, Yuasa T, Iwamura A, Shibata E, Ohba H: Narrow CSF space at high convexity and high midline areas in idiopathic normal pressure hydrocephalus detected by axial and coronal MRI. Neuroradiology 50: 117-122, 2008 
89) Vassilouthis J: The syndrome of normal-pressure hydrocephalus. J Neurosurg 61: 501-509, 1984

90) Caruso R, Cervoni L, Vitale AM, Salvati M: Idiopathic normal-pressure hydrocephalus in adults: result of shunting correlated with clinical findings in 18 patients and review of the literature. Neurosurg Rev 20: 104-107, 1997

91) Holodny AI, Waxman R, George AE, Rusinek H, Kalnin AJ, de Leon M: MR differential diagnosis of normal-pressure hydrocephalus and Alzheimer disease: significance of perihippocampal fissures. AJNR Am J Neuroradiol 19: 813-819, 1998

92) Ishii K, Kawaguchi T, Shimada K, et al.: Voxel-based analysis of gray matter and CSF space in idiopathic normal pressure hydrocephalus. Dement Geriatr Cogn Disord 25: 329-335, 2008

93) Yamashita F, Sasaki M, Takahashi S, et al.: Detection of changes in cerebrospinal fluid space in idiopathic normal pressure hydrocephalus using voxel-based morphometry. Neuroradiology 52: 381-386, 2010

94) Lee WJ, Wang SJ, Hsu LC, Lirng JF, Wu CH, Fuh JL: Brain MRI as a predictor of CSF tap test response in patients with idiopathic normal pressure hydrocephalus. J Neurol 257: 1675-1681, 2010

95) Craven CL, Toma AK, Mostafa T, Patel N, Watkins LD: The predictive value of DESH for shunt responsiveness in idiopathic normal pressure hydrocephalus. J Clin Neurosci 34: 294-298, 2016

96) Ishii K, Kanda T, Harada A, et al.: Clinical impact of the callosal angle in the diagnosis of idiopathic normal pressure hydrocephalus. Eur Radiol 18: 2678-2683, 2008

97) Virhammar J, Laurell K, Cesarini KG, Larsson EM: The callosal angle measured on MRI as a predictor of outcome in idiopathic normal-pressure hydrocephalus. J Neurosurg 120: 178-184, 2014

98) Virhammar J, Laurell K, Cesarini KG, Larsson EM: Preoperative prognostic value of MRI findings in 108 patients with idiopathic normal pressure hydrocephalus. AJNR Am J Neuroradiol 35: 2311-2318, 2014

99) Yamada S, Ishikawa M, Yamamoto K: Optimal diagnostic indices for idiopathic normal pressure hydrocephalus based on the $3 \mathrm{D}$ quantitative volumetric analysis for the cerebral ventricle and subarachnoid space. AJNR Am J Neuroradiol 36: 2262-2269, 2015

100) Yamada $S$, Ishikawa $M$, Yamamoto K: Comparison of CSF distribution between idiopathic normal pressure hydrocephalus and Alzheimer disease. AJNR Am J Neuroradiol 37: 1249-1255, 2016

101) Yamada S, Ishikawa M, Yamamoto K: Fluid distribution pattern in adult-onset congenital, idiopathic, and secondary normal-pressure hydrocephalus: implications for clinical care. Front Neurol 8: 583, 2017

102) Adachi M, Kawanami T, Ohshima F, Kato T: Upper midbrain profile sign and cingulate sulcus sign: MRI findings on sagittal images in idiopathic normal-pressure hydrocephalus, Alzheimer's disease, and progressive supranuclear palsy. Radiat Med 24: 568-572, 2006

103) Savolainen S, Laakso MP, Paljärvi L, et al.: MR imaging of the hippocampus in normal pressure hydrocephalus: correlations with cortical Alzheimer's disease confirmed by pathologic analysis. AJNR Am J Neuroradiol 21: 409-414, 2000

104) Lee PH, Yong SW, Ahn YH, Huh K: Correlation of midbrain diameter and gait disturbance in patients with idiopathic normal pressure hydrocephalus. $J$ Neurol 252: 958-963, 2005

105) Mocco J, Tomey MI, Komotar RJ, et al.: Ventriculoperitoneal shunting of idiopathic normal pressure hydrocephalus increases midbrain size: a potential mechanism for gait improvement. Neurosurgery 59: 847-850; discussion 850-851, 2006

106) Ishii M, Kawamata T, Akiguchi I, et al.: Parkinsonian symptomatology may correlate with CT findings before and after shunting in idiopathic normal pressure hydrocephalus. Parkinsons Dis 2010, 201089, 2010

107) Hiraoka K, Yamasaki H, Takagi M, et al.: Is the midbrain involved in the manifestation of gait disturbance in idiopathic normal-pressure hydrocephalus? J Neurol 258: 820-825, 2011

108) Yamada $S$, Ishikawa $M$, Iwamuro $Y$, Yamamoto $K$ : Choroidal fissure acts as an overflow device in cerebrospinal fluid drainage: morphological comparison between idiopathic and secondary normal-pressure hydrocephalus. Sci Rep 6: 39070, 2016

109) Serulle Y, Rusinek H, Kirov II, et al.: Differentiating shunt-responsive normal pressure hydrocephalus from Alzheimer disease and normal aging: pilot study using automated MRI brain tissue segmentation. J Neurol 261: 1994-2002, 2014

110) Ishii K, Soma T, Shimada K, Oda H, Terashima A, Kawasaki R: Automatic volumetry of the cerebrospinal fluid space in idiopathic normal pressure hydrocephalus. Dement Geriatr Cogn Dis Extra 3: 489-496, 2013

111) Krauss JK, Regel JP, Vach W, et al.: White matter lesions in patients with idiopathic normal pressure hydrocephalus and in an age-matched control group: a comparative study. Neurosurgery 40: 491-495; discussion 495-496, 1997

112) Tullberg M, Jensen C, Ekholm S, Wikkelsø C: Normal pressure hydrocephalus: vascular white matter changes on MR images must not exclude patients from shunt surgery. AJNR Am J Neuroradiol 22: 1665-1673, 2001

113) Hoza D, Vlasák A, Hořínek D, Sameš M, Alfieri A: DTI-MRI biomarkers in the search for normal pressure hydrocephalus aetiology: a review. Neurosurg Rev 38: 239-244, discussion 244, 2015

114) Siasios I, Kapsalaki EZ, Fountas KN, et al.: The role of diffusion tensor imaging and fractional anisotropy in the evaluation of patients with idiopathic normal pressure hydrocephalus: a literature review. Neurosurg Focus 41: E12, 2016

115) Keong NC, Pena A, Price SJ, Czosnyka M, Czosnyka Z, Pickard JD: Imaging normal pressure hydrocephalus: theories, techniques, and challenges. Neurosurg Focus 41: E11, 2016

116) Kim MJ, Seo SW, Lee KM, et al.: Differential diagnosis of idiopathic normal pressure hydrocephalus 
from other dementias using diffusion tensor imaging. AJNR Am J Neuroradiol 32: 1496-1503, 2011

117) Hattori T, Yuasa T, Aoki S, et al.: Altered microstructure in corticospinal tract in idiopathic normal pressure hydrocephalus: comparison with Alzheimer disease and Parkinson disease with dementia. AJNR Am J Neuroradiol 32: 1681-1687, 2011

118) Hattori T, Ito K, Aoki $S$, et al.: White matter alteration in idiopathic normal pressure hydrocephalus: tractbased spatial statistics study. AJNR Am J Neuroradiol 33: 97-103, 2012

119) Scheel M, Diekhoff T, Sprung C, Hoffmann KT: Diffusion tensor imaging in hydrocephalus-findings before and after shunt surgery. Acta Neurochir (Wien) 154: 1699-1706, 2012

120) Koyama T, Marumoto K, Domen K, Miyake H: White matter characteristics of idiopathic normal pressure hydrocephalus: a diffusion tensor tract-based spatial statistic study. Neurol Med Chir (Tokyo) 53: 601-608, 2013

121) Nicot B, Bouzerar R, Gondry-Jouet C, et al.: Effect of surgery on periventricular white matter in normal pressure hydrocephalus patients: comparison of two methods of DTI analysis. Acta Radiol 55: 614-621, 2014

122) Jurcoane A, Keil F, Szelenyi A, Pfeilschifter W, Singer OC, Hattingen E: Directional diffusion of corticospinal tract supports therapy decisions in idiopathic normal-pressure hydrocephalus. Neuroradiology 56: 5-13, 2014

123) Daouk J, Chaarani B, Zmudka J, et al.: Relationship between cerebrospinal fluid flow, ventricles morphology, and DTI properties in internal capsules: differences between Alzheimer's disease and normal-pressure hydrocephalus. Acta Radiol 55: 992-999, 2014

124) Radovnický T, Adámek D, Derner M, Sameš M: Fractional anisotropy in patients with disproportionately enlarged subarachnoid space hydrocephalus. Acta Neurochir (Wien) 158: 1495-1500, 2016

125) Nakanishi A, Fukunaga I, Hori M, et al.: Microstructural changes of the corticospinal tract in idiopathic normal pressure hydrocephalus: a comparison of diffusion tensor and diffusional kurtosis imaging. Neuroradiology 55: 971-976, 2013

126) Hori M, Kamiya K, Nakanishi A, et al.: Prospective estimation of mean axon diameter and extra-axonal space of the posterior limb of the internal capsule in patients with idiopathic normal pressure hydrocephalus before and after a lumboperitoneal shunt by using q-space diffusion MRI. Eur Radiol 26: 2992-2998, 2016

127) Kamiya K, Kamagata K, Miyajima M, et al.: Diffusional kurtosis imaging in idiopathic normal pressure hydrocephalus: correlation with severity of cognitive impairment. Magn Reson Med Sci 15: 316-323, 2016

128) Irie R, Tsuruta K, Hori M, et al.: Neurite orientation dispersion and density imaging for evaluation of corticospinal tract in idiopathic normal pressure hydrocephalus. Jpn J Radiol 35: 25-30, 2017
129) Algin O, Hakyemez B, Parlak M: The efficiency of PCMRI in diagnosis of normal pressure hydrocephalus and prediction of shunt response. Acad Radiol 17: 181-187, 2010

130) Forner Giner J, Sanz-Requena R, Flórez N, et al.: Quantitative phase-contrast MRI study of cerebrospinal fluid flow: a method for identifying patients with normal-pressure hydrocephalus. Neurologia 29: 68-75, 2014

131) Hayashi N, Matsumae M, Yatsushiro S, Hirayama A, Abdullah A, Kuroda K: Quantitative analysis of cerebrospinal fluid pressure gradients in healthy volunteers and patients with normal pressure hydrocephalus. Neurol Med Chir (Tokyo) 55: 657-662, 2015

132) Sharma AK, Gaikwad S, Gupta V, Garg A, Mishra NK: Measurement of peak CSF flow velocity at cerebral aqueduct, before and after lumbar CSF drainage, by use of phase-contrast MRI: utility in the management of idiopathic normal pressure hydrocephalus. Clin Neurol Neurosurg 110: 363-368, 2008

133) Scollato A, Tenenbaum R, Bahl G, Celerini M, Salani B, Di Lorenzo N: Changes in aqueductal CSF stroke volume and progression of symptoms in patients with unshunted idiopathic normal pressure hydrocephalus. AJNR Am J Neuroradiol 29: 192197, 2008

134) Scollato A, Gallina P, Gautam B, et al.: Changes in aqueductal CSF stroke volume in shunted patients with idiopathic normal-pressure hydrocephalus. AJNR Am J Neuroradiol 30: 1580-1586, 2009

135) Tawfik AM, Elsorogy L, Abdelghaffar R, Naby AA, Elmenshawi I: Phase-contrast MRI CSF flow measurements for the diagnosis of normal-pressure hydrocephalus: observer agreement of velocity versus volume parameters. AJR Am J Roentgenol 208: 838843, 2017

136) Lenfeldt N, Hauksson J, Birgander R, Eklund A, Malm J: Improvement after cerebrospinal fluid drainage is related to levels of N-acetyl-aspartate in idiopathic normal pressure hydrocephalus. Neurosurgery 62: 135-141, discussion 141-142, 2008

137) Lundin F, Tisell A, Dahlqvist Leinhard O, et al.: Reduced thalamic N-acetylaspartate in idiopathic normal pressure hydrocephalus: a controlled $1 \mathrm{H}-\mathrm{mag}-$ netic resonance spectroscopy study of frontal deep white matter and the thalamus using absolute quantification. J Neurol Neurosurg Psychiatry 82: 772-778, 2011

138) Kizu O, Yamada K, Nishimura T: Proton chemical shift imaging in normal pressure hydrocephalus. AJNR Am J Neuroradiol 22: 1659-1664, 2001

139) Algin O, Hakyemez B, Parlak M: Proton MR spectroscopy and white matter hyperintensities in idiopathic normal pressure hydrocephalus and other dementias. Br J Radiol 83: 747-752, 2010

140) Lundin F, Tisell A, Leijon G, et al.: Preoperative and postoperative $1 \mathrm{H}-\mathrm{MR}$ spectroscopy changes in frontal deep white matter and the thalamus in idiopathic normal pressure hydrocephalus. J Neurol Neurosurg Psychiatry 84: 188-193, 2013 
141) Ohmichi T, Kondo M, Itsukage M, et al.: Usefulness of the convexity apparent hyperperfusion sign in 123I-iodoamphetamine brain perfusion SPECT for the diagnosis of idiopathic normal pressure hydrocephalus. J Neurosurg 130: 398-405, 2018

142) Takahashi R, Ishii K, Tokuda T, Nakajima M, Okada T: SINPHONI-2 Investigators: Regional dissociation between the cerebral blood flow and gray matter density alterations in idiopathic normal pressure hydrocephalous: results from SINPHONI-2 study. Neuroradiology 61: 37-42, 2019

143) Ishii K, Hashimoto M, Hayashida K, et al.: A multicenter brain perfusion SPECT study evaluating idiopathic normal-pressure hydrocephalus on neurological improvement. Dement Geriatr Cogn Disord 32: 1-10, 2011

144) Yamada SM, Masahira N, Kawanishi Y, Fujimoto Y, Shimizu K: Preoperative acetazolamide SPECT is useful for predicting outcome of shunt operation in idiopathic normal pressure hydrocephalus patients. Clin Nucl Med 38: 671-676, 2013

145) Sakakibara R, Uchida Y, Ishii K, et al.: Bladder recovery relates with increased mid-cingulate perfusion after shunt surgery in idiopathic normal-pressure hydrocephalus: a single-photon emission tomography study. Int Urol Nephrol 48: 169-174, 2016

146) Sakakibara R, Uchida Y, Ishii K, et al.: Correlation of right frontal hypoperfusion and urinary dysfunction in iNPH: a SPECT study. Neurourol Urodyn 31: 50-55, 2012

147) Tatsch K, Poepperl G: Nigrostriatal dopamine terminal imaging with dopamine transporter SPECT: an update. J Nucl Med 54: 1331-1338, 2013

148) Townley RA, Botha H, Graff-Radford J, et al.: 18F-FDG PET-CT pattern in idiopathic normal pressure hydrocephalus. Neuroimage Clin 18: 897-902, 2018

149) Calcagni ML, Lavalle M, Mangiola A, et al.: Early evaluation of cerebral metabolic rate of glucose (CMRglu) with 18F-FDG PET/CT and clinical assessment in idiopathic normal pressure hydrocephalus (INPH) patients before and after ventricular shunt placement: preliminary experience. Eur J Nucl Med Mol Imaging 39: 236-241, 2012

150) Calcagni ML, Taralli S, Mangiola A, et al.: Regional cerebral metabolic rate of glucose evaluation and clinical assessment in patients with idiopathic normal-pressure hydrocephalus before and after ventricular shunt placement: a prospective analysis. Clin Nucl Med 38: 426-431, 2013

151) Hiraoka K, Narita W, Kikuchi H, et al.: Amyloid deposits and response to shunt surgery in idiopathic normal-pressure hydrocephalus. J Neurol Sci 356: 124-128, 2015

152) Rinne JO, Frantzen J, Leinonen V, et al.: Prospective flutemetamol positron emission tomography and histopathology in normal pressure hydrocephalus. Neurodegener Dis 13: 237-245, 2014

153) Leinonen V, Rinne JO, Virtanen KA, et al.: Positron emission tomography with [18F]flutemetamol and [11C]PiB for in vivo detection of cerebral cortical amyloid in normal pressure hydrocephalus patients. Eur J Neurol 20: 1043-1052, 2013

154) Wong DF, Moghekar AR, Rigamonti D, et al.: An in vivo evaluation of cerebral cortical amyloid with [18F]flutemetamol using positron emission tomography compared with parietal biopsy samples in living normal pressure hydrocephalus patients. Mol Imaging Biol 15: 230-237, 2013

155) Agostini V, Lanotte M, Carlone M, et al.: Instrumented gait analysis for an objective pre-/postassessment of tap test in normal pressure hydrocephalus. Arch Phys Med Rehabil 96: 1235-1241, 2015

156) Allali G, Laidet M, Armand S, et al.: A combined cognitive and gait quantification to identify normal pressure hydrocephalus from its mimics: hte Geneva's protocol. Clin Neurol Neurosurg 160: 5-11, 2017

157) Damasceno BP, Carelli EF, Honorato DC, Facure JJ: The predictive value of cerebrospinal fluid tap-test in normal pressure hydrocephalus. Arq Neuropsiquiatr 55: 179-185, 1997

158) Gallagher R, Marquez J, Osmotherly P: Clinimetric properties and minimal clinically important differences for a battery of gait, balance, and cognitive examinations for the tap test in idiopathic normal pressure hydrocephalus. Neurosurgery 84: E378E384, 2019

159) Gallina P, Lastrucci G, Caini S, Lorenzo ND, Porfirio B, Scollato A: Accuracy and safety of 1-day external lumbar drainage of CSF for shunt selection in patients with idiopathic normal pressure hydrocephalus. Journal Neurosurg, Epub 2018 Nov 1; doi: 10.3171/2018.6.JNS18400.

160) Haan J, Thomeer RT: Predictive value of temporary external lumbar drainage in normal pressure hydrocephalus. Neurosurgery 22: 388-391, 1988

161) Ishikawa M, Oowaki H, Matsumoto A, Suzuki T, Furuse M, Nishida N: Clinical significance of cerebrospinal fluid tap test and magnetic resonance imaging/computed tomography findings of tight high convexity in patients with possible idiopathic normal pressure hydrocephalus. Neurol Med Chir (Tokyo) 50: 119-123, disucussion 123, 2010

162) Ishikawa M, Yamada S, Yamamoto K: Early and delayed assessments of quantitative gait measures to improve the tap test as a predictor of shunt effectiveness in idiopathic normal pressure hydrocephalus. Fluids Barriers CNS 13: 20, 2016

163) Kang K, Ko PW, Jin M, Suk K, Lee HW: Idiopathic normal-pressure hydrocephalus, cerebrospinal fluid biomarkers, and the cerebrospinal fluid tap test. J Clin Neurosci 21: 1398-1403, 2014

164) Lenfeldt N, Larsson A, Nyberg L, et al.: Idiopathic normal pressure hydrocephalus: increased supplementary motor activity accounts for improvement after CSF drainage. Brain 131: 2904-2912, 2008

165) Mahr CV, Dengl M, Nestler U, et al.: Idiopathic normal pressure hydrocephalus: diagnostic and predictive value of clinical testing, lumbar drainage, and CSF dynamics. J Neurosurg 125: 591-597, 2016 
166) Malm J, Kristensen B, Karlsson T, Fagerlund M, Elfverson J, Ekstedt J: The predictive value of cerebrospinal fluid dynamic tests in patients with th idiopathic adult hydrocephalus syndrome. Arch Neurol 52: 783789, 1995

167) Matsuoka T, Akakabe M, Iida JI, Kawahara M, Uchiyama Y: Changes in cognitive function scores after cerebrospinal fluid tap testing in patients with suspected idiopathic normal-pressure hydrocephalus. Cogn Behav Neurol 31: 201-206, 2018

168) Mendes GAS, de Oliveira MF, Pinto FCG: The Timed Up and Go test as a diagnostic criterion in normal pressure hydrocephalus. World Neurosurg 105: 456-461, 2017

169) Mihalj M: CSF tap test - obsolete or appropriate test for predicting shunt responsiveness? A systemic review. J Neurol Sci 370: 157, 2016

170) Raneri F, Zella MAS, Di Cristofori A, Zarino B, Pluderi M, Spagnoli D: Supplementary tests in idiopathic normal pressure hydrocephalus: a single-center experience with a combined lumbar infusion test and tap test. World Neurosurg 100: 567-574, 2017

171) Ravdin LD, Katzen HL, Jackson AE, Tsakanikas D, Assuras S, Relkin NR: Features of gait most responsive to tap test in normal pressure hydrocephalus. Clin Neurol Neurosurg 110: 455-461, 2008

172) Sand T, Bovim G, Grimse R, Myhr G, Helde G, Cappelen J: Idiopathic normal pressure hydrocephalus: the CSF tap-test may predict the clinical response to shunting. Acta Neurol Scand 89: 311-316, 1994

173) Schniepp R, Trabold R, Romagna A, et al.: Walking assessment after lumbar puncture in normal-pressure hydrocephalus: a delayed improvement over 3 days. J Neurosurg 126: 148-157, 2017

174) Scully AE, Lim ECW, Teow PP, Tan DML: A systematic review of the diagnostic utility of simple tests of change after trial removal of cerebrospinal fluid in adults with normal pressure hydrocephalus. Clin Rehabil 32: 942-953, 2018

175) Thakur SK, Serulle Y, Miskin NP, Rusinek H, Golomb J, George AE: Lumbar puncture test in normal pressure hydrocephalus: does the volume of CSF removed affect the response to tap? AJNR Am J Neuroradiol 38: 1456-1460, 2017

176) Virhammar J, Cesarini KG, Laurell K: The CSF tap test in normal pressure hydrocephalus: evaluation time, reliability and the influence of pain. Eur J Neurol 19: 271-276, 2012

177) Wikkelsø C, Andersson H, Blomstrand C, Lindqvist G: The clincial effect of lumbar puncture in normal pressure hydrocephalus. J Neurol Neurosurg Psychiatry 45: 64-69, 1982

178) Wikkelsø C, Hellström P, Klinge PM, Tans JT: European iNPH Multicentre Study Group: The European iNPH Multicentre Study on the predictive values of resistance to CSF outflow and the CSF tap test in patients with idiopathic normal pressure hydrocephalus. J Neurol Neurosurg Psychiatry 84: 562-568, 2013

179) Wolfsegger T, Topakian R: Cognitive impairment predicts worse short-term response to spinal tap test in normal pressure hydrocephalus. J Neurol Sci 379: 222-225, 2017

180) Yamada $S$, Ishikawa $M$, Miyajima $M$, et al.: Disease duration: the key to accurate CSF tap test in iNPH. Acta Neurol Scand 135: 189-196, 2017

181) Clinical guideposts for the practicing neurologist. Neurol Clin Pract 7: 1, 2017

182) Lopes MIR, Tornai JB, Jeng FLM, et al.: Development of the Brazilian Portuguese version of the "Grading scale for idiopathic normal pressure hydrocephalus": cross-cultural adaptation, reliability and validity. Arq Neuropsiquiatr 76: 692-696, 2018

183) Yamada S, Kimura T, Jingami N, et al.: Disability risk or unimproved symptoms following shunt surgery in patients with idiopathic normal-pressure hydrocephalus: post hoc analysis of SINPHONI-2. J Neurosurg 126: 2002-2009, 2017

184) Yamada S, Ishikawa M, Miyajima M et al.: Timed up and go test at tap test and shunt surgery in idiopathic normal pressure hydrocephalus. Neurol Clin Pract 7: 1-11, 2017

185) Williams MA, Malm J: Diagnosis and treatment of idiopathic normal pressure hydrocephalus. Continuum (Minneap Minn) 22: 579-599, 2016

186) Panciani PP, Migliorati K, Muratori A, Gelmini M, Padovani A, Fontanella M: Computerized gait analysis with inertial sensor in the management of idiopathic normal pressure hydrocephalus. Eur J Phys Rehabil Med 54: 724-729, 2018

187) Weerakkody RA, Czosnyka M, Schuhmann MU, et al.: Clinical assessment of cerebrospinal fluid dynamics in hydrocephalus. Guide to interpretation based on observational study. Acta Neurol Scand 124: 85-98, 2011

188) Pisani R, Mazzone P, Cocito L: Continuous lumbar cerebrospinal fluid pressure monitoring in idiopathic normal-pressure hydrocephalus: predictive value in the selection for shunt surgery. Clin Neurol Neurosurg 100: 160-162, 1998

189) Krauss JK, Droste DW, Bohus M, et al.: The relation of intracranial pressure B-waves to different sleep stages in patients with suspected normal pressure hydrocephalus. Acta Neurochir (Wien) 136: 195203, 1995

190) Eide PK, Stanisic M: Cerebral microdialysis and intracranial pressure monitoring in patients with idiopathic normal-pressure hydrocephalus: association with clinical response to extended lumbar drainage and shunt surgery. J Neurosurg 112: 414424, 2010

191) Eide PK, Fremming AD, Sorteberg A: Lack of relationship between resistance to cerebrospinal fluid outflow and intracranial pressure in normal pressure hydrocephalus. Acta Neurol Scand 108: 381-388, 2003

192) Poca MA, Mataró M, Del Mar Matarín M, Arikan F, Junqué C, Sahuquillo J: Is the placement of shunts in patients with idiopathic normal-pressure hydrocephalus worth the risk? Results of a study based on continuous monitoring of intracranial pressure. $J$ Neurosurg 100: 855-866, 2004 
193) Sahuquillo J, Rubio E, Codina A, et al.: Reappraisal of the intracranial pressure and cerebrospinal fluid dynamics in patients with the so-called "normal pressure hydrocephalus" syndrome. Acta Neurochir (Wien) 112: 50-61, 1991

194) Black PM, Ojemann RG, Tzouras A: CSF shunts for dementia, incontinence, and gait disturbance. Clin Neurosurg 32: 632-651, 1985

195) Bárcena A, Mestre C, Cañizal JM, Rivero B, Lobato RD: Idiopathic normal pressure hydrocephalus: analysis of factors related to cerebrospinal fluid dynamics determining functional prognosis. Acta Neurochir (Wien) 139: 933-941, 1997

196) Delwel EJ, de Jong DA, Avezaat CJ: The prognostic value of clinical characteristics and parameters of cerebrospinal fluid hydrodynamics in shunting for idiopathic normal pressure hydrocephalus. Acta Neurochir (Wien) 147: 1037-1042; discussion 1042-1043, 2005

197) Brean A, Eide PK: Assessment of idiopathic normal pressure patients in neurological practice: the role of lumbar infusion testing for referral of patients to neurosurgery. Eur J Neurol 15: 605-612, 2008

198) Eide PK: Intracranial pressure parameters in idiopathic normal pressure hydrocephalus patients treated with ventriculo-peritoneal shunts. Acta Neurochir (Wien) 148: 21-29, discussion 29, 2006

199) Anile C, De Bonis P, Albanese A, et al.: Selection of patients with idiopathic normal-pressure hydrocephalus for shunt placement: a single-institution experience. J Neurosurg 113: 64-73, 2010

200) Kahlon B, Sundbärg G, Rehncrona S: Comparison between the lumbar infusion and CSF tap tests to predict outcome after shunt surgery in suspected normal pressure hydrocephalus. J Neurol Neurosurg Psychiatry 73: 721-726, 2002

201) Takeuchi T, Kasahara E, Iwasaki M, Mima T, Mori K: Indications for shunting in patients with idiopathic normal pressure hydrocephalus presenting with dementia and brain atrophy (atypical idiopathic normal pressure hydrocephalus). Neurol Med Chir (Tokyo) 40: 38-46; discussion 46-47, 2000

202) Børgesen SE: Conductance to outflow of CSF in normal pressure hydrocephalus. Acta Neurochir (Wien) 71: 1-45, 1984

203) Miyake H, Ohta T, Kajimoto Y, Deguchi J: Diamox((R)) challenge test to decide indications for cerebrospinal fluid shunting in normal pressure hydrocephalus. Acta Neurochir (Wien) 141: 1187-1193, 1999

204) Jeppsson A, Zetterberg H, Blennow K, Wikkelsø C: Idiopathic normal-pressure hydrocephalus: pathophysiology and diagnosis by CSF biomarkers. Neurology 80: 1385-1392, 2013

205) Jeppsson A, Höltta M, Zetterberg H, Blennow K, Wikkelsø C, Tullberg M: Amyloid mis-metabolism in idiopathic normal pressure hydrocephalus. Fluids Barriers CNS 13: 13, 2016

206) Pyykkö OT, Lumela M, Rummukainen J, et al.: Cerebrospinal fluid biomarker and brain biopsy findings in idiopathic normal pressure hydrocephalus. PLoS One 9: e91974, 2014
207) Agren-Wilsson A, Lekman A, Sjöberg W, et al.: CSF biomarkers in the evaluation of idiopathic normal pressure hydrocephalus. Acta Neurol Scand 116: 333-339, 2007

208) Akiba C, Nakajima M, Miyajima M, et al.: Change of amyloid- $\beta$ 1-42 toxic conformer ratio after cerebrospinal fluid diversion predicts long-term cognitive outcome in patients with idiopathic normal pressure hydrocephalus. J Alzheimers Dis 63: 989-1002, 2018

209) Lim TS, Choi JY, Park SA, et al.: Evaluation of coexistence of Alzheimer's disease in idiopathic normal pressure hydrocephalus using ELISA analyses for CSF biomarkers. BMC Neurol 14: 66, 2014

210) Miyajima M, Nakajima M, Ogino I, Miyata H, Motoi $Y$, Arai H: Soluble amyloid precursor protein $\alpha$ in the cerebrospinal fluid as a diagnostic and prognostic biomarker for idiopathic normal pressure hydrocephalus. Eur J Neurol 20: 236-242, 2013

211) Tsai A, Malek-Ahmadi M, Kahlon V, Sabbagh MN: Differences in cerebrospinal fluid biomarkers between clinically diagnosed idiopathic normal pressure hydrocephalus and Alzheimer's disease. $J$ Alzheimers Dis Parkinsonism 4: 1000150, 2014

212) Kapaki EN, Paraskevas GP, Tzerakis NG, et al.: Cerebrospinal fluid tau, phospho-tau181 and beta-amyloid1-42 in idiopathic normal pressure hydrocephalus: a discrimination from Alzheimer's disease. Eur J Neurol 14: 168-173, 2007

213) Lins H, Wichart I, Bancher C, Wallesch CW, Jellinger KA, Rösler N: Immunoreactivities of amyloid beta peptide((1-42)) and total tau protein in lumbar cerebrospinal fluid of patients with normal pressure hydrocephalus. J Neural Transm (Vienna) 111: 273-280, 2004

214) Santangelo R, Cecchetti G, Bernasconi MP, et al.: Cerebrospinal fluid amyloid- $\beta$ 42, total tau and phosphorylated tau are low in patients with normal pressure hydrocephalus: analogies and differences with Alzheimer's disease. J Alzheimers Dis 60: 183-200, 2017

215) Ray B, Reyes PF, Lahiri DK: Biochemical studies in normal pressure hydrocephalus (NPH) patients: change in CSF levels of amyloid precursor protein (APP), amyloid-beta (A $\beta$ ) peptide and phospho-tau. J Psychiatr Res 45: 539-547, 2011

216) Jingami N, Asada-Utsugi M, Uemura K, et al.: Idiopathic normal pressure hydrocephalus has a different cerebrospinal fluid biomarker profile from Alzheimer's disease. J Alzheimers Dis 45: 109-115, 2015

217) Chen Z, Liu C, Zhang J, Relkin N, Xing Y, Li Y: Cerebrospinal fluid $A \beta 42$, t-tau, and p-tau levels in the differential diagnosis of idiopathic normal-pressure hydrocephalus: a systematic review and meta-analysis. Fluids Barriers CNS 14: 13, 2017

218) Li X, Miyajima M, Mineki R, Taka H, Murayama K, Arai $\mathrm{H}$ : Analysis of potential diagnostic biomarkers in cerebrospinal fluid of idiopathic normal pressure hydrocephalus by proteomics. Acta Neurochir (Wien) 148: 859-864, discussion 864, 2006 
219) Nagata Y, Bundo M, Sugiura S, et al.: PTPRQ as a potential biomarker for idiopathic normal pressure hydrocephalus. Mol Med Rep 16: 3034-3040, 2017

220) Futakawa S, Nara K, Miyajima M, et al.: A unique N-glycan on human transferrin in CSF: a possible biomarker for iNPH. Neurobiol Aging 33: 1807-1815, 2012

221) Pfanner T, Henri-Bhargava A, Borchert S: Cerebrospinal fluid biomarkers as predictors of shunt response in idiopathic normal pressure hydrocephalus: a systematic review. Can J Neurol Sci 45: 3-10, 2018

222) Tisell M, Tullberg M, Hellström P, Edsbagge M, Högfeldt M, Wikkelsö C: Shunt surgery in patients with hydrocephalus and white matter changes. J Neurosurg 114: 1432-1438, 2011

223) Hung AL, Vivas-Buitrago T, Adam A, et al.: Ventriculoatrial versus ventriculoperitoneal shunt complications in idiopathic normal pressure hydrocephalus. Clin Neurol Neurosurg 157: 1-6, 2017

224) Kluge S, Baumann HJ, Regelsberger J, et al.: Pulmonary hypertension after ventriculoatrial shunt implantation. J Neurosurg 113: 1279-1283, 2010

225) Pascual JM, Prakash UB: Development of pulmonary hypertension after placement of a ventriculoatrial shunt. Mayo Clin Proc 68: 1177-1182, 1993

226) Samtleben W, Bauriedel G, Bosch T, Goetz C, Klare B, Gurland HJ: Renal complications of infected ventriculoatrial shunts. Artif Organs 17: 695-701, 1993

227) Haffner D, Schindera F, Aschoff A, Matthias S, Waldherr R, Schärer K: The clinical spectrum of shunt nephritis. Nephrol Dial Transplant 12: 1143-1148, 1997

228) Burström G, Andresen M, Bartek J, Jr, Fytagoridis A: Subacute bacterial endocarditis and subsequent shunt nephritis from ventriculoatrial shunting 14 years after shunt implantation. BMJ Case Rep 2014, bcr2014204655, 2014

229) Tudor KI, Tudor M, McCleery J, Car J: Endoscopic third ventriculostomy (ETV) for idiopathic normal pressure hydrocephalus (iNPH). Cochrane Database Syst Rev 7: CD010033, 2015

230) Kageyama H, Miyajima M, Ogino I, et al.: Panventriculomegaly with a wide foramen of Magendie and large cisterna magna. J Neurosurg 124: 1858-1866, 2016

231) Chan AK, McGovern RA, Zacharia BE, et al.: Inferior short-term safety profile of endoscopic third ventriculostomy compared with ventriculoperitoneal shunt placement for idiopathic normal-pressure hydrocephalus: a population-based study. Neurosurgery 73: 951-960; discussion 960-961, 2013

232) Pollack IF, Albright AL, Adelson PD: A randomized, controlled study of a programmable shunt valve versus a conventional valve for patients with hydrocephalus. Hakim-Medos Investigator Group. Neurosurgery 45: 1399-1408; discussion 1408-1411, 1999

233) Ringel F, Schramm J, Meyer B: Comparison of programmable shunt valves vs standard valves for communicating hydrocephalus of adults: a retrospective analysis of 407 patients. Surg Neurol 63: 36-41, discussion 41, 2005
234) Xu H, Wang ZX, Liu F, Tan GW, Zhu HW, Chen DH: Programmable shunt valves for the treatment of hydrocephalus: a systematic review. Eur J Paediatr Neurol 17: 454-461, 2013

235) Li M, Wang H, Ouyang Y, Yin M, Yin X: Efficacy and safety of programmable shunt valves for hydrocephalus: a meta-analysis. Int J Surg 44: 139-146, 2017

236) Giordan E, Palandri G, Lanzino G, Murad MH, Elder BD: Outcomes and complications of different surgical treatments for idiopathic normal pressure hydrocephalus: a systematic review and meta-analysis. J Neurosurg, Epub 2018 Nov 1; doi: 10.3171/2018.5.JNS1875.

237) Serarslan Y, Yilmaz A, Çakır M, et al.: Use of programmable versus nonprogrammable shunts in the management of normal pressure hydrocephalus: a multicenter retrospective study with cost-benefit analysis in Turkey. Medicine (Baltimore) 96: e8185, 2017

238) Lemcke J, Meier U, Müller C, et al.: Safety and efficacy of gravitational shunt valves in patients with idiopathic normal pressure hydrocephalus: a pragmatic, randomised, open label, multicentre trial (SVASONA). J Neurol Neurosurg Psychiatry 84: 850-857, 2013

239) Delwel EJ, de Jong DA, Dammers R, Kurt E, van den Brink W, Dirven CMF: A randomised trial of high and low pressure level settings on an adjustable ventriculoperitoneal shunt valve for idiopathic normal pressure hydrocephalus: results of the Dutch evaluation programme Strata shunt (DEPSS) trial. J Neurol Neurosurg Psychiatry 84: 813-817, 2013

240) Toma AK, Tarnaris A, Kitchen ND, Watkins LD: Use of the proGAV shunt valve in normal-pressure hydrocephalus. Neurosurgery 68: 245-249, 2011

241) Suchorska B, Kunz M, Schniepp R, et al.: Optimized surgical treatment for normal pressure hydrocephalus: comparison between gravitational and differential pressure valves. Acta Neurochir (Wien) 157: 703-709, 2015

242) Freimann FB, Vajkoczy P, Sprung C: Patients benefit from low-pressure settings enabled by gravitational valves in normal pressure hydrocephalus. Clin Neurol Neurosurg 115: 1982-1986, 2013

243) Bozhkov Y, Roessler K, Hore N, Buchfelder M, Brandner S: Neurological outcome and frequency of overdrainage in normal pressure hydrocephalus directly correlates with implanted ventriculo-peritoneal shunt valve type. Neurol Res 39: 601-605, 2017

244) Trost HA, Sprung C, Lanksch W, Stolke D, Miethke C: Dual-switch valve: clinical performance of a new hydrocephalus valve. Acta Neurochir Suppl 71: 360363, 1998

245) Lund-Johansen M, Svendsen F, Wester K: Shunt failures and complications in adults as related to shunt type, diagnosis, and the experience of the surgeon. Neurosurgery 35: 839-844, discussion 844, 1994

246) Weiner HL, Constantini S, Cohen H, Wisoff JH: Current treatment of normal-pressure hydrocephalus: comparison of flow-regulated and differential-pressure shunt valves. Neurosurgery 37: 877-884, 1995 
247) Janson CG, Romanova LG, Rudser KD, Haines SJ: Improvement in clinical outcomes following optimal targeting of brain ventricular catheters with intraoperative imaging. J Neurosurg 120: 684-696, 2014

248) Wilson TJ, McCoy KE, Al-Holou WN, Molina SL, Smyth MD, Sullivan SE: Comparison of the accuracy and proximal shunt failure rate of freehand placement versus intraoperative guidance in parietooccipital ventricular catheter placement. Neurosurg Focus 41: E10, 2016

249) Wan KR, Toy JA, Wolfe R, Danks A: Factors affecting the accuracy of ventricular catheter placement. J Clin Neurosci 18: 485-488, 2011

250) Jeremiah KJ, Cherry CL, Wan KR, Toy JA, Wolfe R, Danks RA: Choice of valve type and poor ventricular catheter placement: modifiable factors associated with ventriculoperitoneal shunt failure. J Clin Neurosci 27: 95-98, 2016

251) Yamada S, Ishikawa M, Yamamoto K: Utility of preoperative simulation for ventricular catheter placement via a parieto-occipital approach in normal-pressure hydrocephalus. Oper Neurosurg (Hagerstown) 16: 647-657, 2019

252) Lind CR, Tsai AM, Law AJ, Lau H, Muthiah K: Ventricular catheter trajectories from traditional shunt approaches: a morphometric study in adults with hydrocephalus. J Neurosurg 108: 930-933, 2008

253) Nesvick CL, Khan NR, Mehta GU, Klimo P, Jr: Image guidance in ventricular cerebrospinal fluid shunt catheter placement: a systematic review and meta-analysis. Neurosurgery 77: 321-331, discussion 331, 2015

254) Wilson TJ, Stetler WR, Al-Holou WN, Sullivan SE, Fletcher JJ: Management of intracranial hemorrhage in patients with left ventricular assist devices. J Neurosurg 118: 1063-1068, 2013

255) Nakajima M, Bando K, Miyajima M, Arai H: Lumboperitoneal shunt placement using computed tomography and fluoroscopy in conscious patients. J Neurosurg 111: 618-622, 2009

256) Kawahara T, Oyoshi T, Atsuchi M, Takasaki K, Arita $\mathrm{K}$ : Use of the guidewire for repositioning displaced spinal catheter during lumboperitoneal shunt placement. Surg Neurol Int 7: 63, 2016

257) Kawahara T, Kawahawa T, Higashi T, et al.: Use of blunt scalp hooks for abdominal procedure in lumboperitoneal shunt placement: technical note. Neurol Med Chir (Tokyo) 54: 552-553, 2014

258) Okamura Y, Maruyama K, Fukuda S, et al.: Detailed standardized protocol to prevent cerebrospinal fluid shunt infection. J Neurosurg, 132: 755-759, 2020

259) Kestle JR, Holubkov R, Douglas Cochrane D, et al.: A new Hydrocephalus Clinical Research Network protocol to reduce cerebrospinal fluid shunt infection. $J$ Neurosurg Pediatr 17: 391-396, 2016

260) Kestle JR, Riva-Cambrin J, Wellons JC, Kulkarni AV, Whitehead WE, Walker ML, Oakes WJ, Drake JM, Luerssen TG, Simon TD, Holubkov R: Hydrocephalus Clinical Research Network: A standardized protocol to reduce cerebrospinal fluid shunt infection: the
Hydrocephalus Clinical Research Network Quality Improvement Initiative. J Neurosurg Pediatr 8: 22-29, 2011

261) Farber SH, Parker SL, Adogwa O, McGirt MJ, Rigamonti D: Effect of antibiotic-impregnated shunts on infection rate in adult hydrocephalus: a single institution's experience. Neurosurgery 69: 625-629, discussion 629, 2011

262) Farahmand D, Qvarlander S, Malm J, Wikkelsö C, Eklund A, Tisell M: Intracranial pressure in hydrocephalus: impact of shunt adjustments and body positions. J Neurol Neurosurg Psychiatry 86: 222-228, 2015

263) Farahmand D, Sæhle T, Eide PK, Tisell M, Hellström P, Wikkelsö C: A double-blind randomized trial on the clinical effect of different shunt valve settings in idiopathic normal pressure hydrocephalus. J Neurosurg 124: 359-367, 2016

264) Zemack G, Romner B: Adjustable valves in normal-pressure hydrocephalus: a retrospective study of 218 patients. Neurosurgery 51: 1392-1400; discussion 1400-1402, 2002

265) Sindou M, Guyotat-Pelissou I, Chidiac A, Goutelle A: Transcutaneous pressure adjustable valve for the treatment of hydrocephalus and arachnoid cysts in adults. Experiences with 75 cases. Acta Neurochir (Wien) 121: 135-139, 1993

266) Tsuji O, Sato K: CSF dynamics in a patient with a programmable shunt. Acta Neurochir Suppl 71: 364367, 1998

267) Miyake H, Ohta T, Kajimoto Y, Nagao K: New concept for the pressure setting of a programmable pressure valve and measurement of in vivo shunt flow performed using a microflowmeter. Technical note. J Neurosurg 92: 181-187, 2000

268) Miyake H, Kajimoto Y, Tsuji M, Ukita T, Tucker A, Ohmura T: Development of a quick reference table for setting programmable pressure valves in patients with idiopathic normal pressure hydrocephalus. Neurol Med Chir (Tokyo) 48: 427-432, discussion 432, 2008

269) Miyake H, Kajimoto Y, Murai H, et al.: Assessment of a quick reference table algorithm for determining initial postoperative pressure settings of programmable pressure valves in patients with idiopathic normal pressure hydrocephalus: SINPHONI subanalysis. Neurosurgery 71: 722-728, discussion 728, 2012

270) Miyake H: Shunt devices for the treatment of adult hydrocephalus: recent progress and characteristics. Neurol Med Chir (Tokyo) 56: 274-283, 2016

271) Sundström N, Malm J, Laurell K, et al.: Incidence and outcome of surgery for adult hydrocephalus patients in Sweden. Br J Neurosurg 31: 21-27, 2017

272) Tarnaris A, Toma AK, Chapman MD, Keir G, Kitchen ND, Watkins LD: Use of cerebrospinal fluid amyloid- $\beta$ and total tau protein to predict favorable surgical outcomes in patients with idiopathic normal pressure hydrocephalus. J Neurosurg 115: 145-150, 2011

273) Klinge P, Hellström P, Tans J, Wikkelsø C: European iNPH Multicentre Study Group: One-year outcome in 
the European multicentre study on iNPH. Acta Neurol Scand 126: 145-153, 2012

274) Nakajima M, Miyajima M, Ogino I, et al.: Cerebrospinal fluid biomarkers for prognosis of long-term cognitive treatment outcomes in patients with idiopathic normal pressure hydrocephalus. J Neurol Sci 357: 88-95, 2015

275) Gölz L, Ruppert FH, Meier U, Lemcke J: Outcome of modern shunt therapy in patients with idiopathic normal pressure hydrocephalus 6 years postoperatively. J Neurosurg 121: 771-775, 2014

276) Liu A, Sankey EW, Jusué-Torres I, et al.: Clinical outcomes after ventriculoatrial shunting for idiopathic normal pressure hydrocephalus. Clin Neurol Neurosurg 143: 34-38, 2016

277) Shaw R, Everingham E, Mahant N, Jacobson E, Owler B: Clinical outcomes in the surgical treatment of idiopathic normal pressure hydrocephalus. J Clin Neurosci 29: 81-86, 2016

278) Kazui H, Kanemoto H, Yoshiyama K, et al.: Association between high biomarker probability of Alzheimer's disease and improvement of clinical outcomes after shunt surgery in patients with idiopathic normal pressure hydrocephalus. J Neurol Sci 369: 236-241, 2016

279) Ishikawa M, Hashimoto M, Mori E, Kuwana N, Kazui $\mathrm{H}$ : The value of the cerebrospinal fluid tap test for predicting shunt effectiveness in idiopathic normal pressure hydrocephalus. Fluids Barriers CNS 9: 1, 2012

280) Nakajima M, Miyajima M, Ogino I, et al.: Preoperative phosphorylated tau concentration in the cerebrospinal fluid can predict cognitive function three years after shunt surgery in patients with idiopathic normal pressure hydrocephalus. J Alzheimers Dis 66: 319-331, 2018

281) Lemcke J, Meier U: Idiopathic normal pressure hydrocephalus (iNPH) and co-morbidity: an outcome analysis of 134 patients. Acta Neurochir Suppl 114: 255-259, 2012

282) Kiefer M, Meier U, Eymann R: Does idiopathic normal pressure hydrocephalus always mean a poor prognosis? Acta Neurochir Suppl 106: 101-106, 2010

283) Stein SC, Burnett MG, Sonnad SS: Shunts in normalpressure hydrocephalus: do we place too many or too few? J Neurosurg 105: 815-822, 2006

284) Williams MA, Sharkey P, van Doren D, Thomas G, Rigamonti D: Influence of shunt surgery on healthcare expenditures of elderly fee-for-service Medicare beneficiaries with hydrocephalus. J Neurosurg 107: 21-28, 2007

285) Kameda M, Yamada S, Atsuchi M, et al.: Cost-effectiveness analysis of shunt surgery for idiopathic normal pressure hydrocephalus based on the SINPHONI and SINPHONI-2 trials. Acta Neurochir (Wien) 159: 995-1003, 2017

286) Tullberg M, Persson J, Petersen J, Hellström P, Wikkelsø C, Lundgren-Nilsson Å: Shunt surgery in idiopathic normal pressure hydrocephalus is costeffective-a cost utility analysis. Acta Neurochir (Wien) 160: 509-518, 2018

Corresponding author: Madoka Nakajima, MD, PhD Department of Neurosurgery, Juntendo University School of Medicine, 2-1-1 Hongo, Bunkyo-ku, Tokyo 113-8342, Japan. e-mail:madoka66@juntendo.ac.jp 